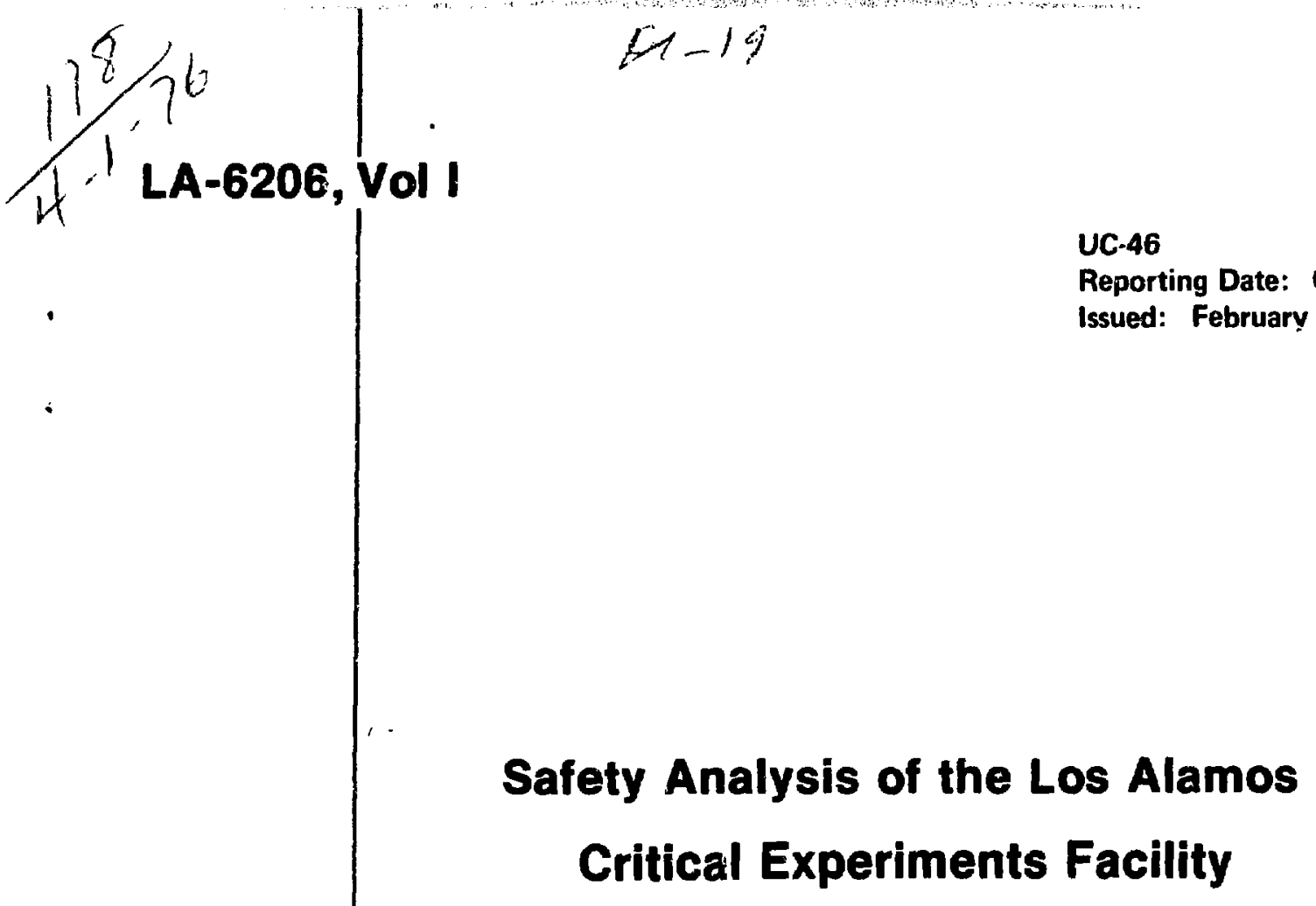

by

Hugh C. Paxton 
Prialed in the United Stater of Amenca. Available trom National Technical Information Service

US Departmont of Commorce

5285 Port Royal Poad

Springtiold, VA 2215!

Price: Printed Copy $\$ 5.00$ Microfiche $\$ 2.26$

This repart wex pregared an en acrauns of wark sponeored on the l'nited Nlales Government. Neither the Uniled State mor the linited slotes fiming Remesrth and Development Adirectors. subrontractors. or their employeen, mater any

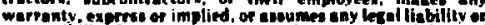

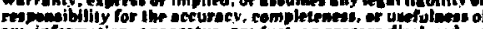
min informution. apparalus, icoduct, of process diuclesed, of meprements that is use would not infrinte privately owned rixhts. 


\section{CONTENTS}

ABSTIRAC:T

BACKGIROIND

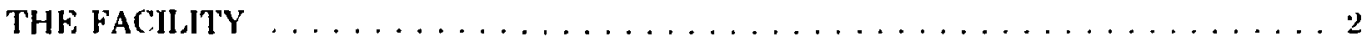

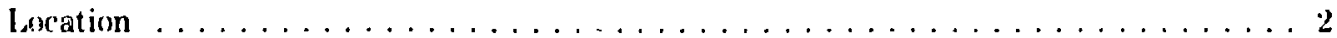

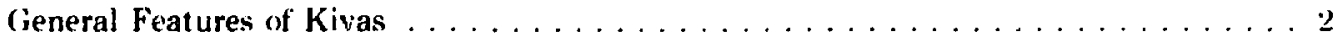

'IYYPICAI, CRITICAL, ASSEMBLIES $\ldots \ldots \ldots \ldots \ldots \ldots \ldots$

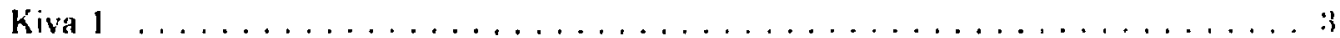

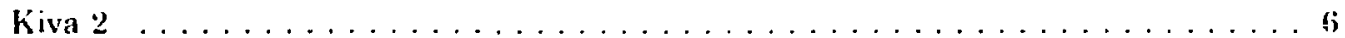

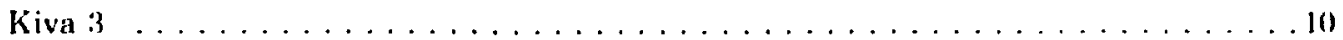

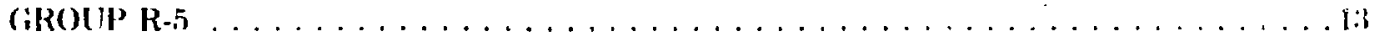

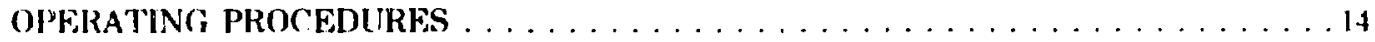

PROTECTION OFFERED BY THE FACIIITY $\ldots \ldots \ldots \ldots \ldots \ldots \ldots$

KINGILT SAFETY ANALYSIS $\ldots \ldots \ldots \ldots \ldots \ldots \ldots \ldots$

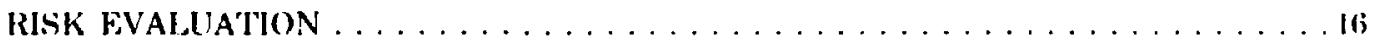

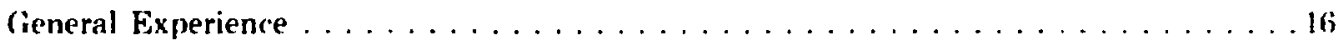

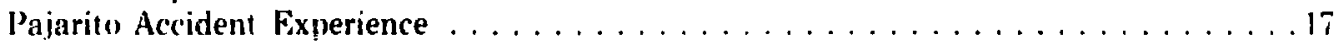

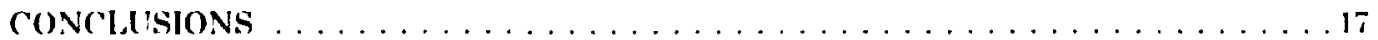

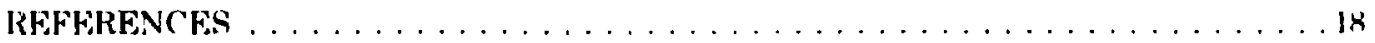

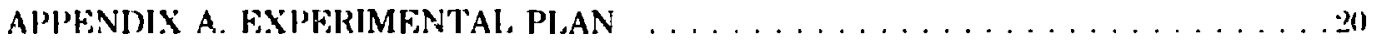

API'FNDIX B. SAFFIY (GUIDF, FOR THE PERFORMANCF, OF

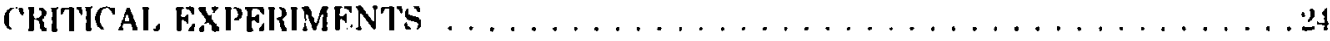

Approved:
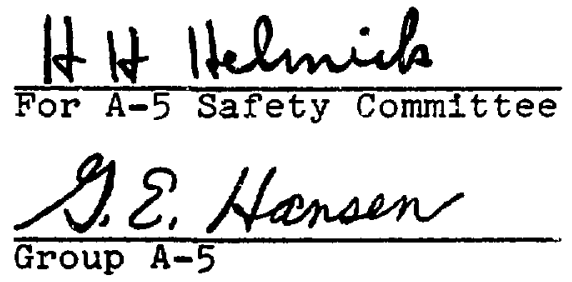

This teport wan prepated as an aorsunt of wozk

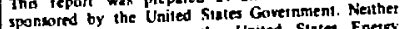
sponiored by suites not the United Stated Enetgs Recath and Derelopment Administritson, nat ans of

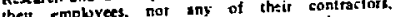
subconincton, or their employees. makes eny mertanty, exptess or impied. or asurnar any ingal

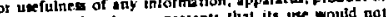

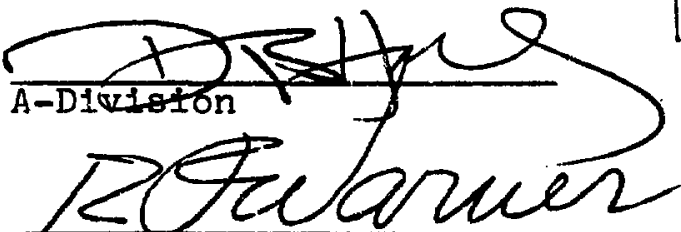
innge sriviely owmed rights.

For LASL Reactor Safeiy Committee 


\title{
SAFETY ANALYSIS OF THE LOS ALAMOS \\ CRITICAL EXPERIMENTS FACIIITY
}

by

\author{
Hugh C. Paxton
}

\begin{abstract}
The safety of Pajarito Site critical assembly operations depends upon protection built into the facility, upon knowledgeable personnel, and upon good practice as defined by operating procedures and experimental plans. Distance, supplemented by shielding in some cases, would protect personnel against an extreme accident generating $10^{19}$ fissions.

During the facility's 28 -year history, the direct cost of criticality accidents has translated to a risk of less than \$200 per year.
\end{abstract}

\section{BACKGROUND}

The Los Alamos Critical Experiments Facility now consists of three independent assembly buildings, called "Kivas," in which assemblies are operated remotely from three separate but grouped control rooms a quarter mile from two Kivas ( 1 and 2) and somewhat less distant from the third. Kiva 1 was first used in 1947. Shortly thereafter, a universal machine called "Topsy" was constructed to investigate enriched uranium meral cores in a thick natural uranium reflector. This machine was later adapted to a nickel reflector and to other cores. As the weapon program expanded and weapon design became more sophisticated, the Laboratory's critical assemblies group, then Group W-2, was called upon to make measurements to (1) aid in the design of experimental nuclear explosive devices, (2) establish nuclearly safe procedures for handling, storing, and transporting weapons, and (3) provide neutron physics parameters necessary for the calculation of weapon systems. The work load soon became more than could be handled in one assembly building, and Kiva 2 was constructed in 1950 , along with the present main laboratory building in which the control rooms are located.

Although work directly related to weapon design continued to be of primary concern, activities gradually broadened. The nuclear safety program was expanded to include safety of active material processing and fabrication operations, both locally and AEC-wide The reactor physics research program developed to include basic infornation on fissile and nonfissile materials of interest in reactor development as well as weapon design, particularly the derivation of consistent parameters for use in multigroup machine calculations.

In 1955 the Rover reactor category was added, and it became a dominant field through 1972, although weapon and nuclear safety responsibilities and other reactor interests were still active. At the beginning of that period. the critical experiments group was transferred from W Division (weapons) to $N$ Division (Rover) and redesignated Group N-2. Demands of the Rover program led to construction of Kiva 3 . in which assembly studies commenced during February 1961.

Upon termination of the Rover program, the group became P-5 (in the Physics Division), and it was transferred twice more in 1975 to become. successively Group A-5 and Group R-5. The last change was part of the plan to focus LASL reactor aclivities in $\mathbf{R}$ Division.

On several occasions, critical assembly machines have been relocated to improve operating efficiency as program emphasis has changed. 


\section{THE FACILITY}

\section{Location}

The Los Alamos critical facility is located at Pajarito Site (TA-18), which is about three miles from the nearest residential area, and about one-quarter mile from the closest technical area (see Fig. 1). It is in an arid canyon, and some natural shielding is afforded by the surrounding canyon walls (Figs. 2 and 3).

\section{General Features of Kivas}

The Kivas are of reintorced concrete and masonry block construction. Each has a traveling crane in the main assembly room. Gas-fired furnaces are used for heating, and forced-diaft ventilation is provided. Kivas 1 and 2 each have provision for storage of active material in a separately locked room, with storage areas for which load limits are posted. Com. binations for outside door locks have limited distribution.

In accordance with operating procedures, a system of tive separate radiation level detectors permanently installed in each Kiva serves the roles of scram actuation and operational instrumentation. Compressed ai: is furnished from a common source. Hydraulic supplies are tailored to the needs of individual machines.

Each Kiva is surrounded by an exclusion area that is vacated before remote operation, and automatic signals forewarn anyone who might be overlooked. When the gate to this area is open, operation is prevented by interlocks and by key-actuated

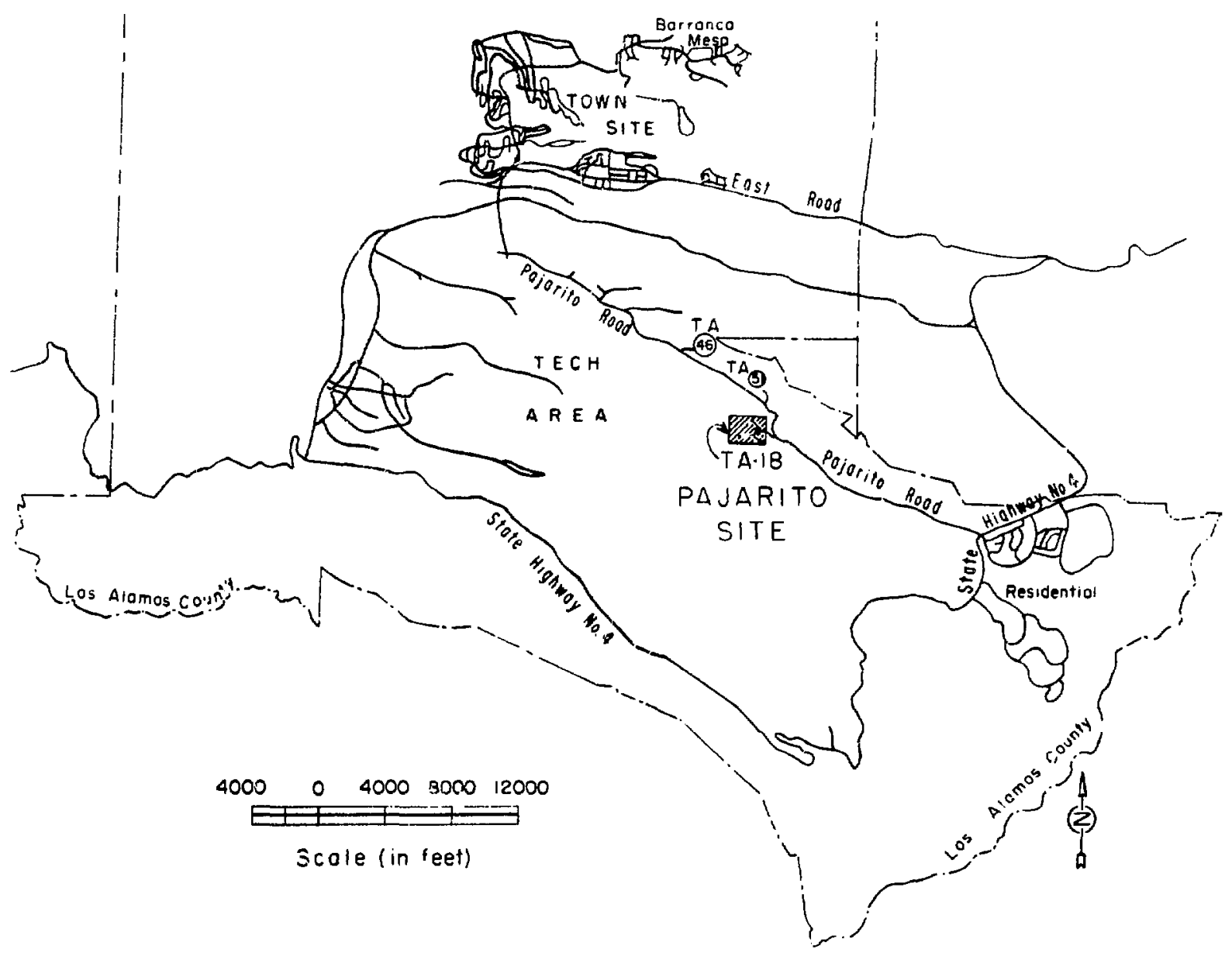

Fig. 1.

Environs of Pajarito Site (TA-18). 


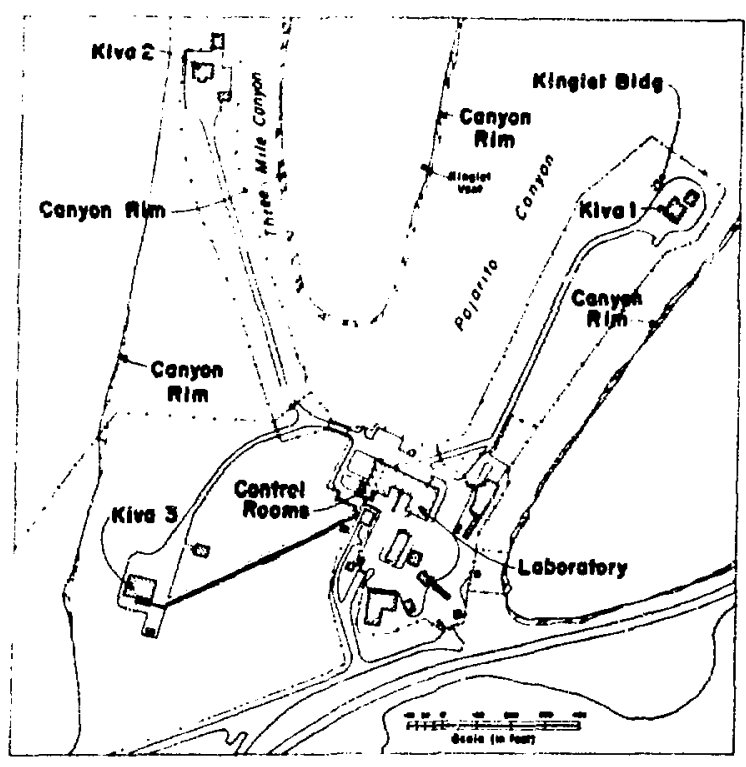

Fig. 2.

Pajarito Site and terrain. switches that require the same (captive) key for supplying power to assemblies and for opening the gate.

\section{TYPICAL CRITICAL ASSEMBLIES}

\section{Kiva I (Fig. 4)}

The distance of about 1000 feet from Kiva 1 to the nearest occupied building is a primary safety feature, as the building itself affords only light shielding.

The following critical assemblies in Kiva 1 are subject to modification as required by changing demands of reactor programs.

1. Honeycomb Assembly (Fig. 5). Honeycumb, a versatile machine for mocking up relatively large critical systems, provides when assembled a 6 -ft cubic matrix of 3 -in. by 3 -in. by 6 -ft aluminum tubes for supporting reactor materials. It has been used since 1968 for a simple graphite and uranium

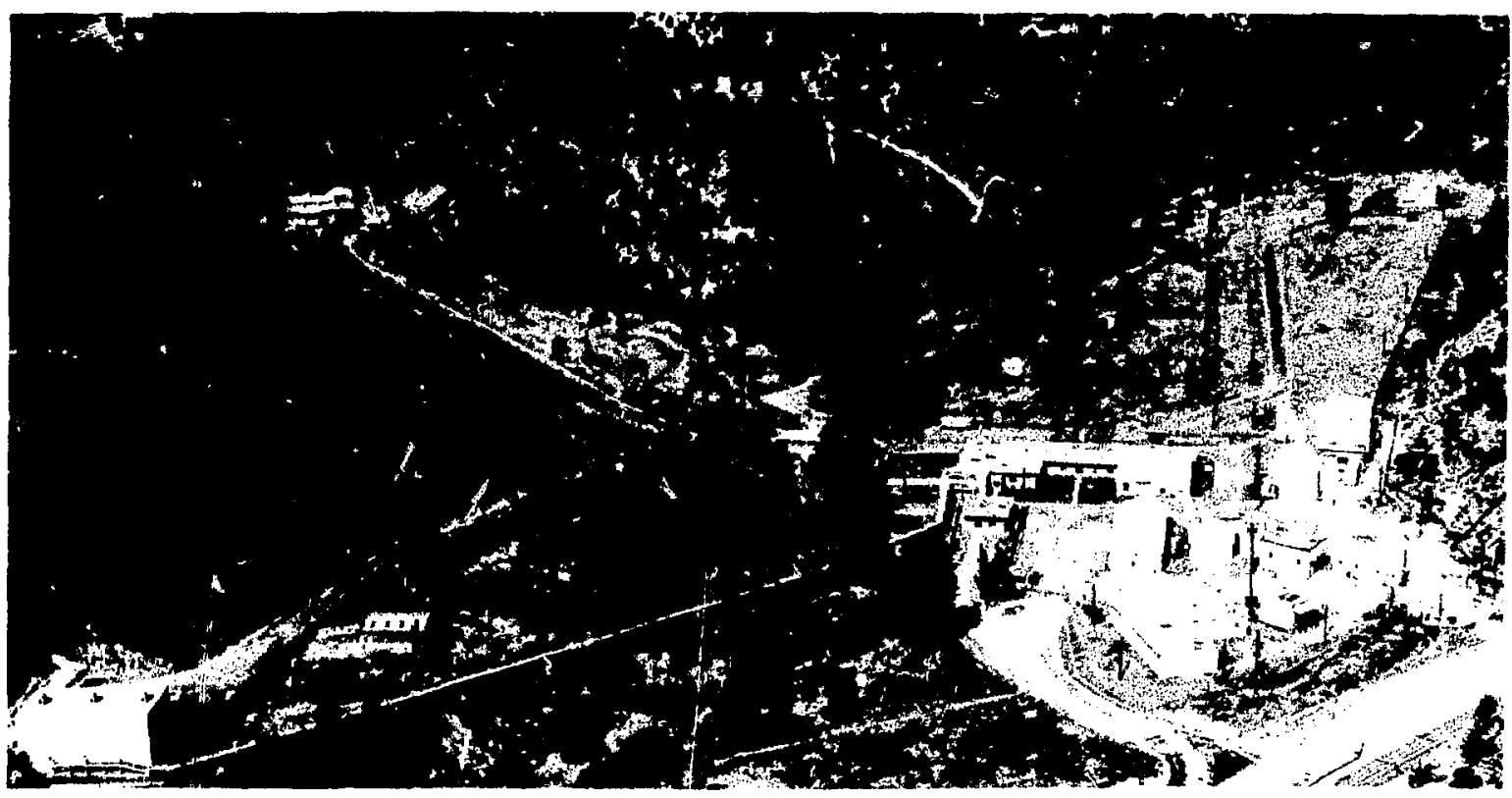

Fig. 3.

Prijarito Site. 1969. Main building with control room is at right center; Kiva 1, right backiround: Kiva 2. left background; and Kiva 3, left foreground. 


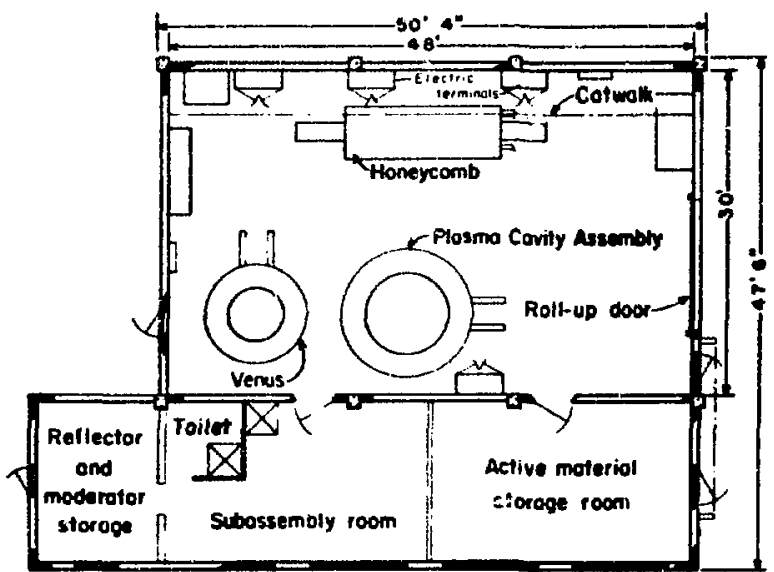

Fig. 4.

Kiva 1 floor plon.

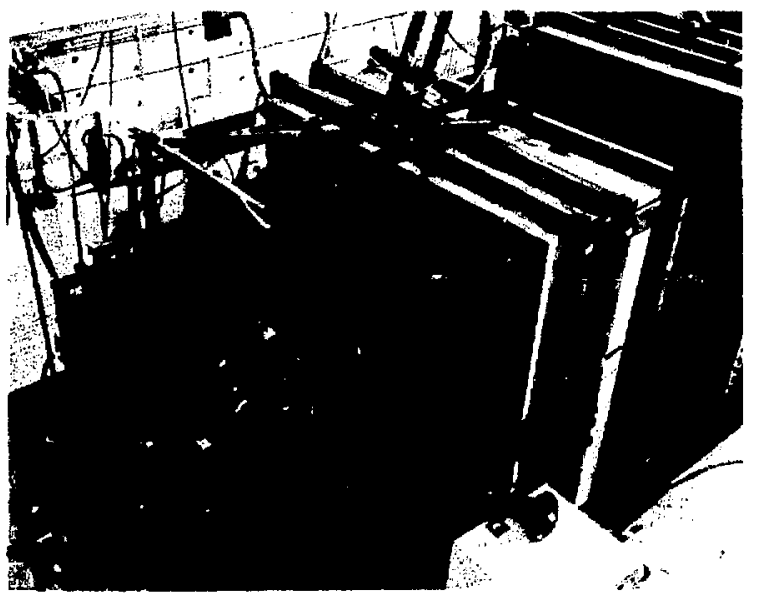

Fig. 5.

Hunevcomb split-table assembly machine.

assembly to give reactor-physics data pertinent to the resonance range of neutron reactions. The assembly is an unreflected 4 - $\mathrm{ft}$ cube of uniformly interleaved graphite plates and $U(93)$ foil, with an overall $\mathrm{C} / 2: 35 \mathrm{U}$ atomic ratio of 180 . It is expected that at least one similar assembly at another $\mathrm{C} / 235 \mathrm{U}$ value will be investigated. Scrams retract one-third of the split assembly horizontally and withdraw fuel bundles (safety rods) worth about $1.5 \$$. The effectiveness of controls is $\sim 0.8 \$$.

2. Venus (Fig. 6). The Venus machine, which last supported the Pewee Z'po assembly. was designed originally for a neutronic mockup of Kiwi-

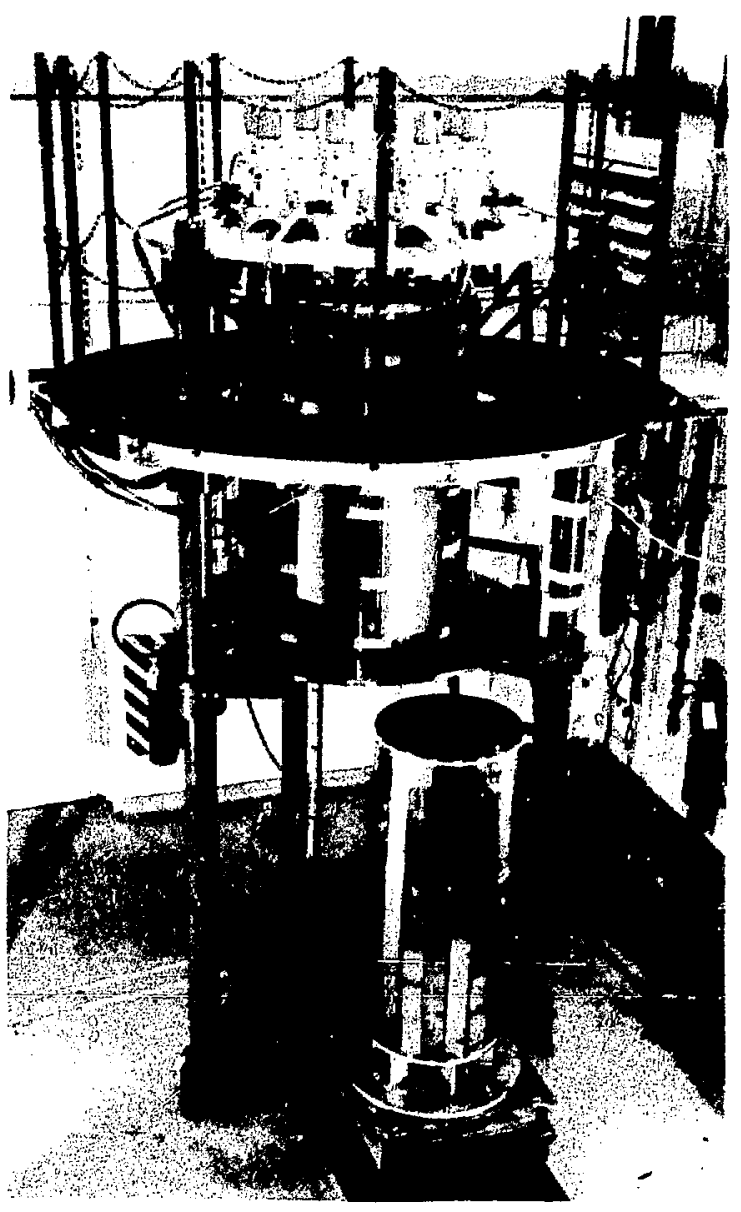

Fig. 6.

Venus machine with Pewee Zepo. Invar strips are attached temporarily to the retracted core.

A. and was then adapted to meckups of Dumbo and an early member of the Kiwi-B series. Powee Zepo simulated the Pewee 2 reactor, designed as a test bed for Rover fuel elements.

The variety of assemblies to which Vinus has been adapted can be extended considerably, indeed beyond the capabilities of the other general-purpose machines, Comet (in Kiva 2) and Supercomet (in Kiva 3). A retracted part of an assembly can be carried upward to a fixed upper portion by means of a nydraulic lift. Alternatively, the retracted part can be moved outward by means of a cart, a convenience for setup and modification. A scram signal causes the lift to drop and also actuates any safety device that has been mounted above (like rewee Zepo). 
3. Plasma Cavity Assembly (Figs. 7 and 8). The Mars macline, used earlier for zero-power mockups of Kiwi-B. Phoebus 1, Phoebus 2, and NFF Zepo reactors, now supports the Plasma Cavity Assembly (P(A). This assembly (more properly, a series of assemblies) is intended to guide the design of a high. power plasma reactor of interest to NASA. The PCA is basically a thick beryllium reflector surrounding a large cavity that may contain a variety of U(93.2) arrangements at low density. As shown in Fig. 7, the reflector is made up of components from a number of Rover reactors and critical assemblies. The outer i)eryllium annulus from Phoebus 2 contains $18 \mathrm{con}$. trol drums that also serve as safety devices.

The init ial core, consisting of $10 \mathrm{U}(33.2)$ foil layers on light aluminum supports, gave a critical mass of $19 \mathrm{~kg}$ of uranium. In Fig. 8, this core is shown retricted from the main reflector body. There was little change in critical mass with the foil on the peripheral wall of the cavity.

Next, the critical mass was reduced to $6.8 \mathrm{~kg}$ of uranium by means of a beryllium annulus within the foil liner, as in Fig. 9. This arrangement can accom. modate a canister containing small quantities of

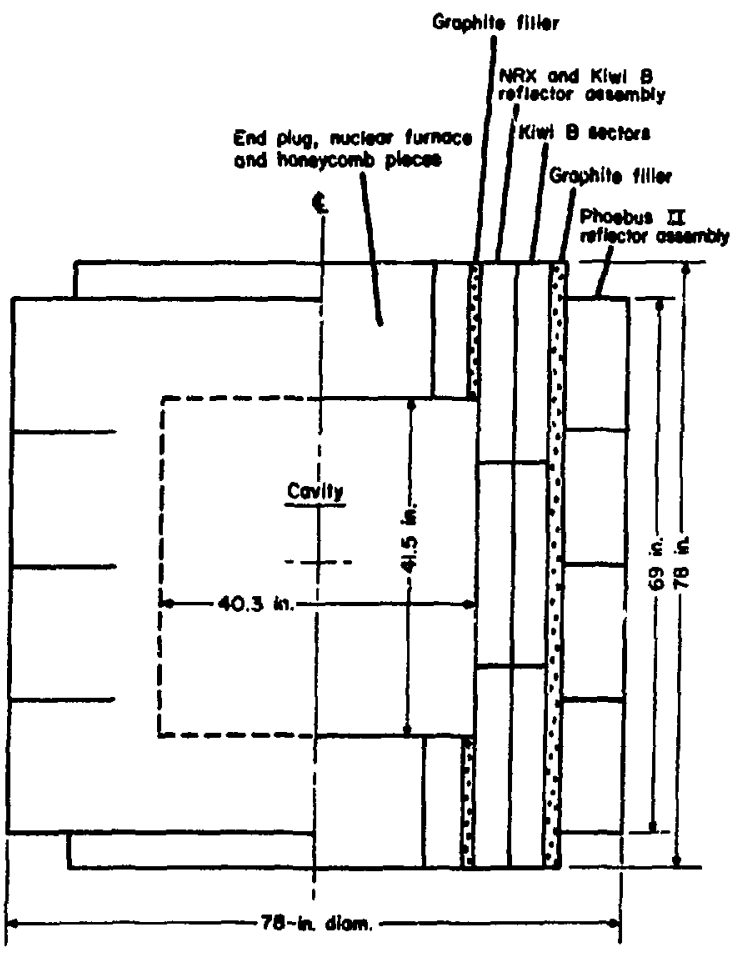

Fig. 7.

Beryllium reflector of the Plasma Cavity Asse'mbly.

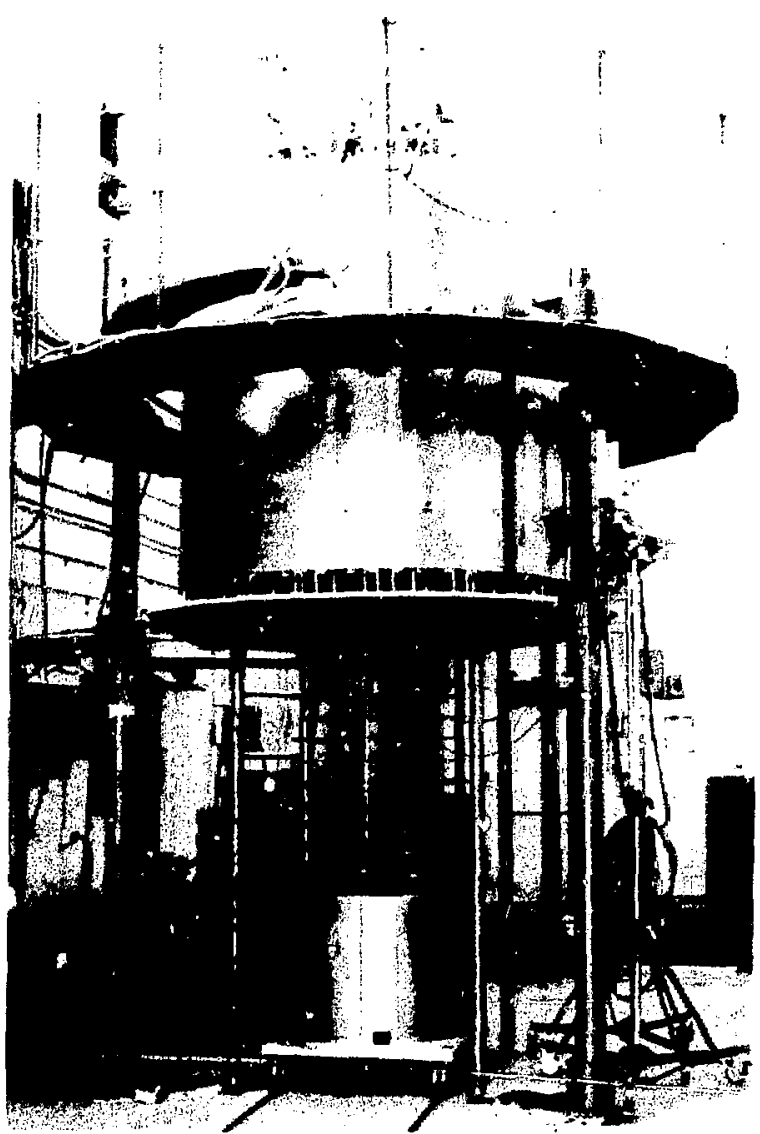

Fig. 8.

Plasma Cavity Assem bly on the Mars machine, with initial core retracted.

$U(93) F_{f}$ to augment $U(93)$ driver foils on the periphery. The worth of thin uranium on the axis is $3.4 \$ / \mathrm{kg}$. six times the value in the driver region. The total reactivity swing of control drums is $4.0 \$$. of which about half would be available for scram from a median position. A scram signal also would retract the core to make the system far subcritical.

4. Kinglet. The Kinglet assembly is set up in special weather-protective housing outside Kiva 1. The original purpose was to provide a feasibility check of the KING high-flux reactor concept, with emphasis on dynamic stability. Like that in KING. the fuel is a circulating enriched-uranium solution (at about $86 \mathrm{~g}{ }^{225}$ U/liter), but Kinglet is scaled down in dimensions and has operational limitations such that no heat exchanger is required. The critical 


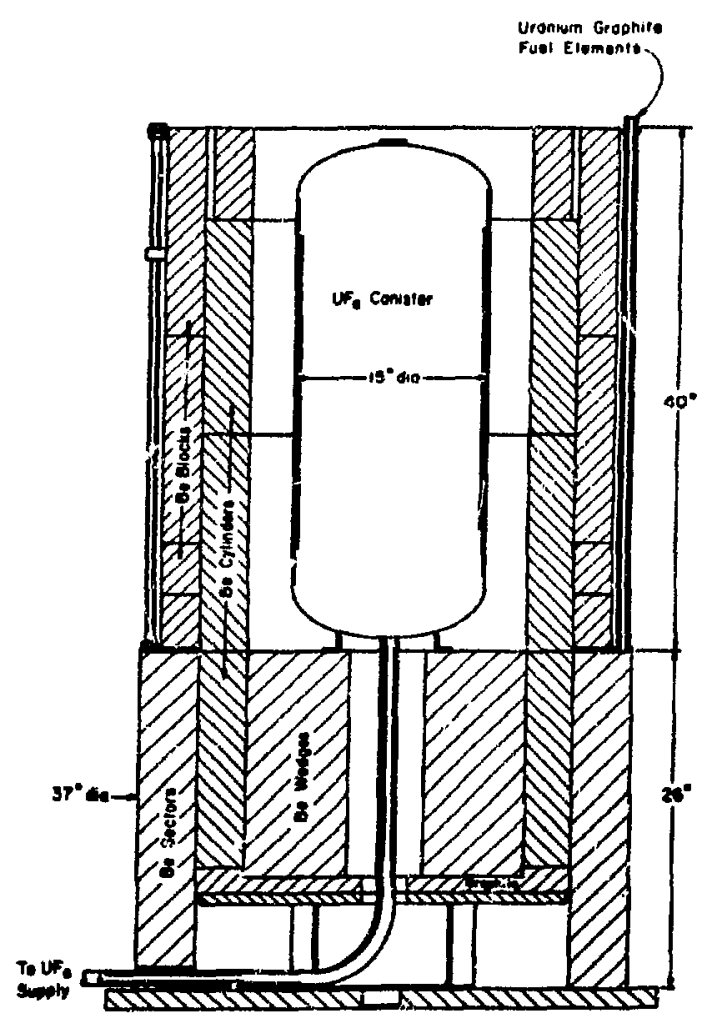

Fig. 9.

PCA core with beryllium annulus and $U F_{6}$ canister.

region (Fig. 10 ) is a Zircaloy nozzle surrounded by a beryllium reflector (to keep the critical diameter small and the attainable linear velocity of solution reasonably large). Other piping and vessels are stainless steel. Solution ejected from the nozzle drains into an annulus dimensioned to be subcritical, from which the fuel pump forces it into another cycle.

A cadmium-coated control cylinder travels between the Zircaloy nozzle and the beryllium reflector. The overall worth is about $18 \$$, of which more than $10 \$$ is available for shutdown. When the fuel pump stops, solution settles to about the midpoint of the 28 -in.-high beryllium reflector, thereby shutting down the system effectively.

At the maximum solution flow rate, 63 liters/s, the entire $\sim 560$-liter inventory traverses the system in 9 $s$, and the transit time through the critical region is

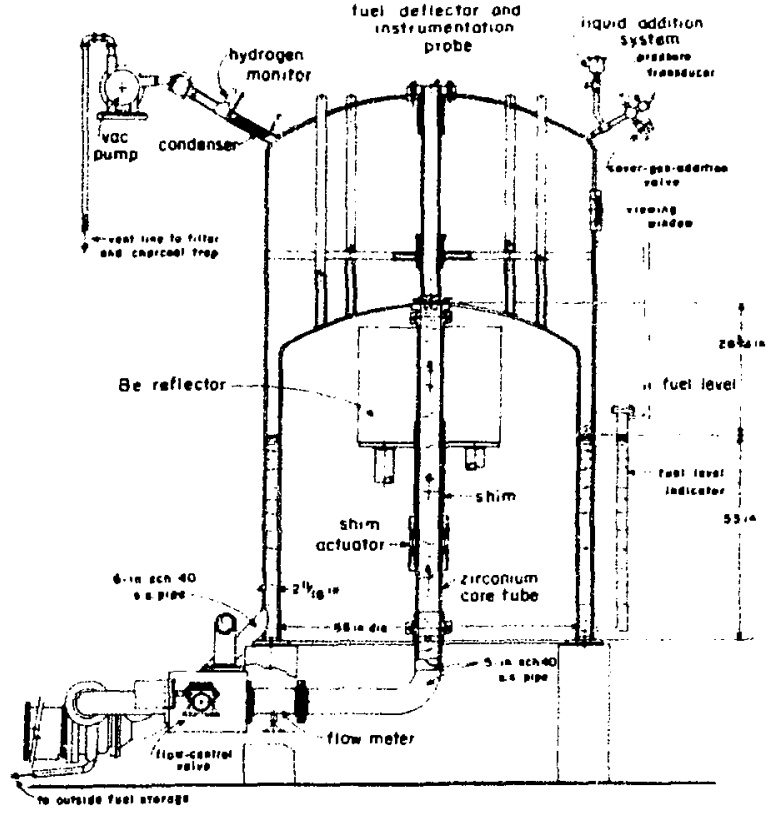

Fig. 10.

Kinglet circulating solution assembly.

approximately $0.1 \mathrm{~s}$. In this condition, mest delayedneutron precursors are swept out and decay before completing the circuit, giving abuit. $2^{\prime \prime}$; of the usual delaved-neutron effectiveness.

Another feature of this assembly, different from others at Pajarito Site, is that appreciable volatile fission-product activity can be releasec' from the fuel during normal operation. Therefore, radioactive gas that collects within the system envelope is held until a Group $\mathrm{H}-1$ representative finds that conditions are acceptable for flushing. Because of these unusual features, a special Kirglet safety analysis report was prepared. ${ }^{\prime}$

\section{Kiva 2 (Fig. 11)}

Kiva 2 is like Kiva $i$ in that masonry walls afford only nominai shielding; consequent ly. the same distance from the nearest occupied building was maintained. The assemblies in this Kiva, listed below. generally grew out of the weapon program. Several (Jezebel, Flattop, and Biy Ten), unlike those of Kiva 1. are not suluject to major modification. 


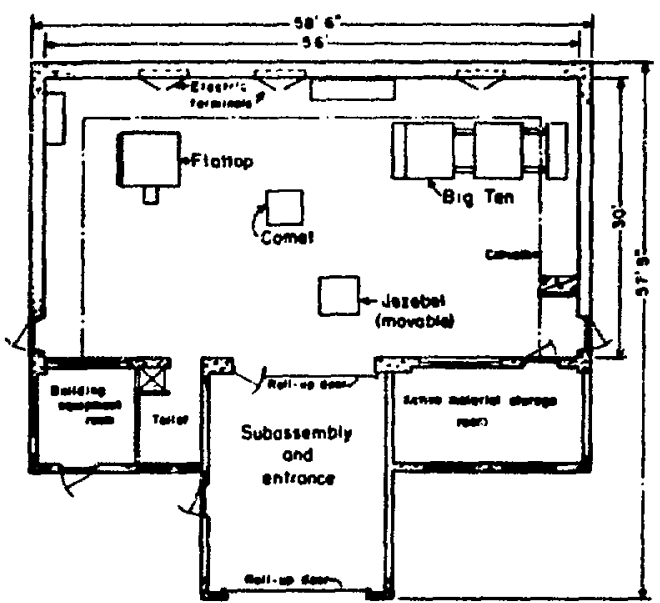

Fig. 11.

Kiva 2 floor plan.

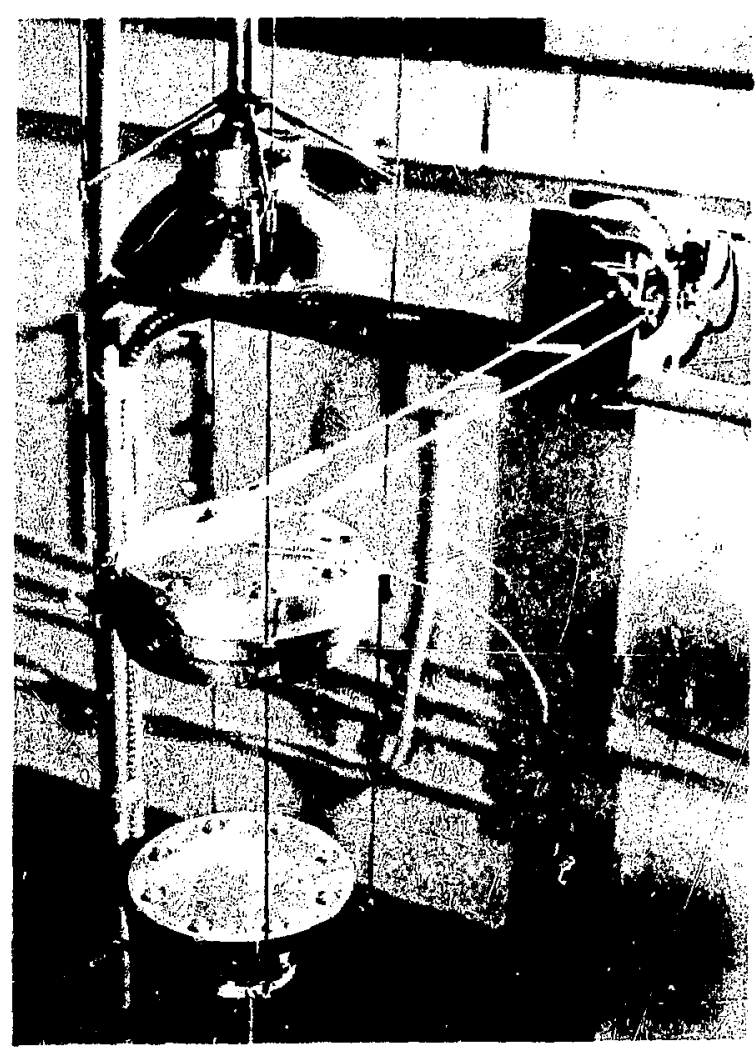

Fig. 12.

The Jezebel bare-plutonium assembly.

\section{Jezebel (Fig. 12)}

Jezebel, an unreflected, nearly spherical assembly of $\delta$-phase plutonium, is used for reactor physics investigations. The original plutonium components, still in service, contain $4.5 \%{ }^{240} \mathrm{Pu}$. Other interchangeable component sets, of plutonium with 21 . ${ }^{240} \mathrm{Pu}$ and of ${ }^{233} \mathrm{U}$ metal, were retired after surveys of characteristics.

An essentially portable machine, Jezebel was first installed in Kiva 1. Scram is effected by separating the sphere into three nearly equal portions by the independent motion of both polar caps of plutonium. The plutonium control rod, which is worth about $0.7 \$$, does not contribute to the scram action.

2. Flattop (Figs. 13 and 14). The Flattop series of assemblies has interchangeable spherical cores of U(93). ${ }^{23: 3} \mathrm{U}$, or plutonium rnetal, surrounded, during remote operation, by a reflector of thick natural uranium. The reflector is subdivided into a stationary hemisphere, irito which the core is recessed, and two movable quadrants. Natural uranium contro! rods, one worth about $1.5 \$$ and two others worth about $0.6 \$$ each, enter the fixed hemisphere from below. Upon scram, both quadrants of the reflector retract rapidly to the normal "disassembled" condition. Flattop is used for fundamental reactor physics studies, and, by irradiations in the known neutron spectra, to provide samples for radiochemical research.

3. Big Ten (Figs. 15 and 16). Big Ten, a large cylindrical metal assembly is mounted, with its axis horizontal, on a split-table machine. It is used to provide cross-section data for a fast neutron spectrum that extends to lower energies than do those of small metal system: such as Jezebel and Flattop.

A large part of the 21 -in.-diam core (Fig. 17) consists of interleaved plates of $U(93)$ and natural uranium that are sized to give $10 \%$ average ${ }^{235} \mathrm{U}$ enrichment. Inserts of homogeneous $U(10)$ contain all regions of internal measurement so that data interpretation will not be complicated by heterogeneity effects. The core is surrounded by a 6 -in.-thick reflector of depleted uranium within which lowvalue control rods and safety rods of the same material are inserted. A more effective uranium contro: rod enters along the core axis.

For calibration and kinetic measurements, during which reactivity changes were sigrificant, a temporary large-value rod, also on the axis, combined 


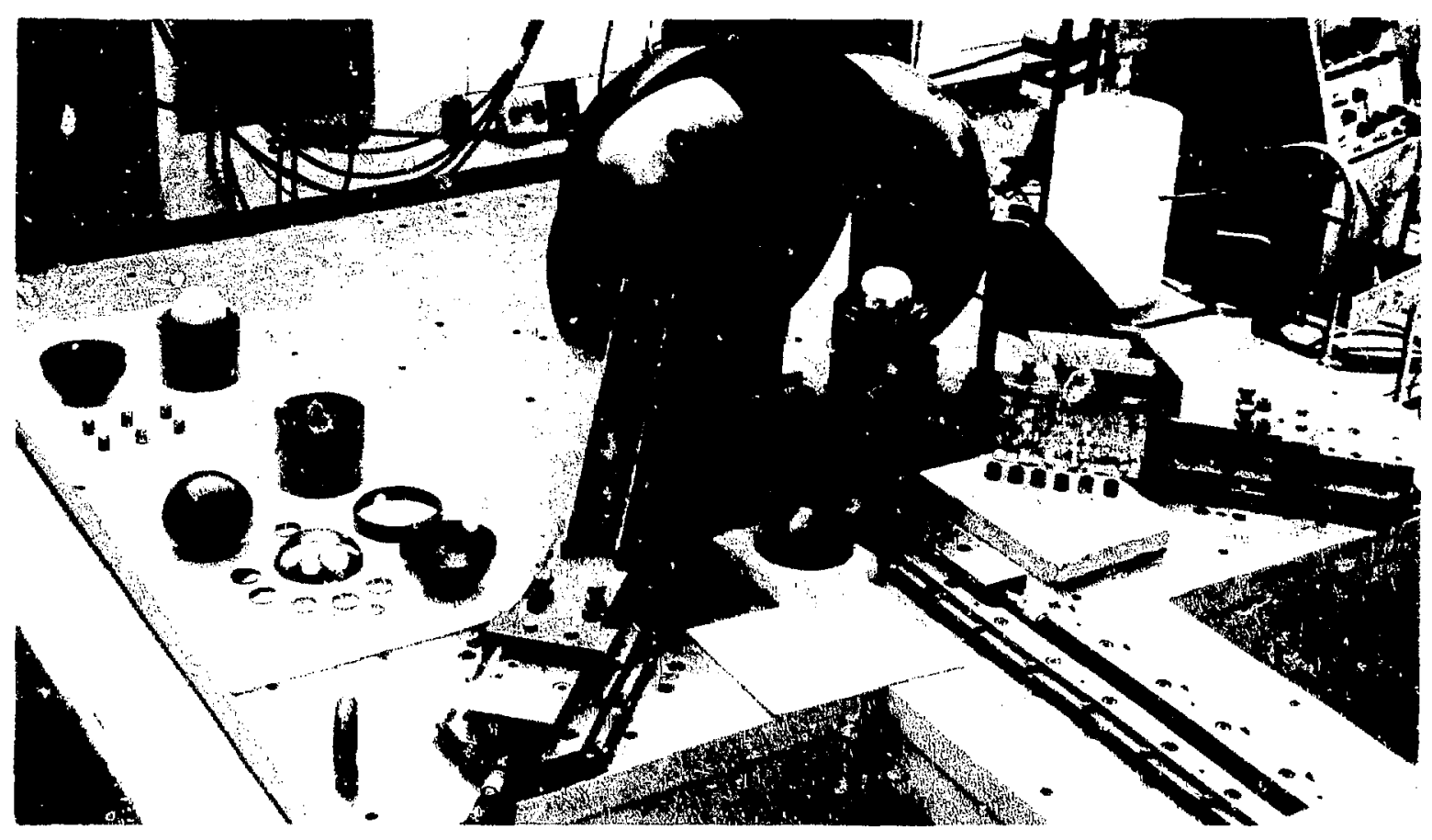

Fig. 13.

Flattop. The plutonium core is in position, other cores and adapters are at left foreground.

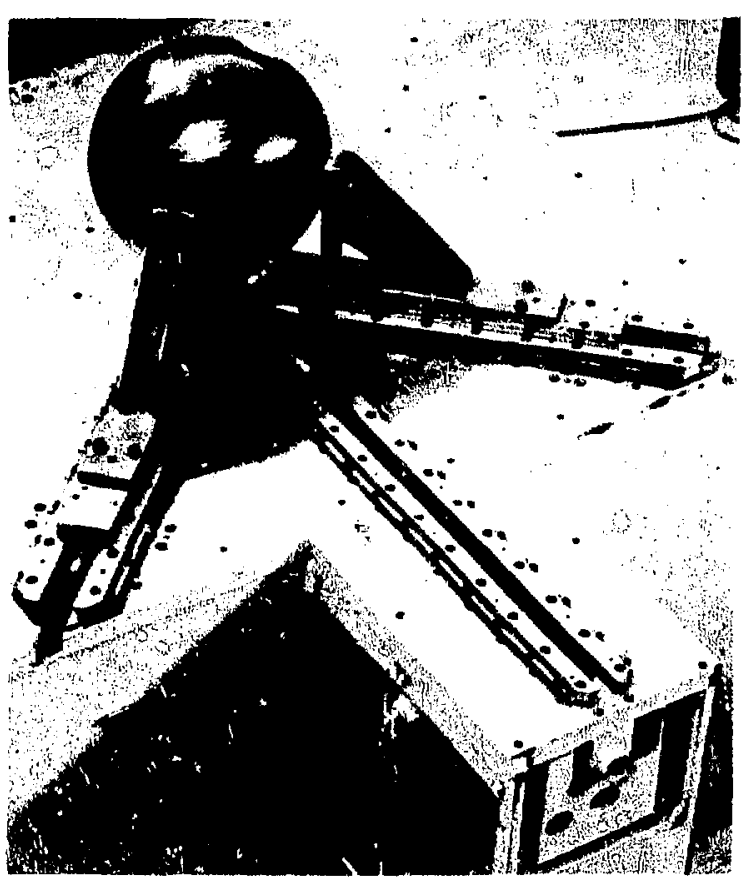

Fig. 14.

Flattop as it appears during remote operation. safety and control functions (Fig. 18). After such measurements were completed, the excess reactivity was decreased from $0.85 \$$ to less than $0.2 \$$, and the large rod was replaced by fixed components so as to reduce perturbations during delicate reactivity coefficient measurements that depart little from delayed criticality.

The major scram mode is subrivision of the assembly by retraction of the movable part of the table. This is backed up by withdrawal of reflector rods worth an estimated 1.0\$. Throughout kinetic measurements, a portion of the temporary rod worth 0.7 to $1.3 \$$ served as a supplementary scram.

4. Comet (Fig. 19). The Comet assembly machine is a hydraulic lift and surrounding supports for an assortment of superstructures that includes thin, taut diaphragms, heavy-duty platforms, and an A-frame. It is adapted to a variety of assemblies by supporting part of the material on the remotely controlled lift and part on as appropriate superstructure. Although it is intended primarily for subcritical measurements such as weapon safety tests, several temporary critical assemblies have been mounted on Comet (Figs. 20 and 21). Each had provision for a backup scram (in addition to 


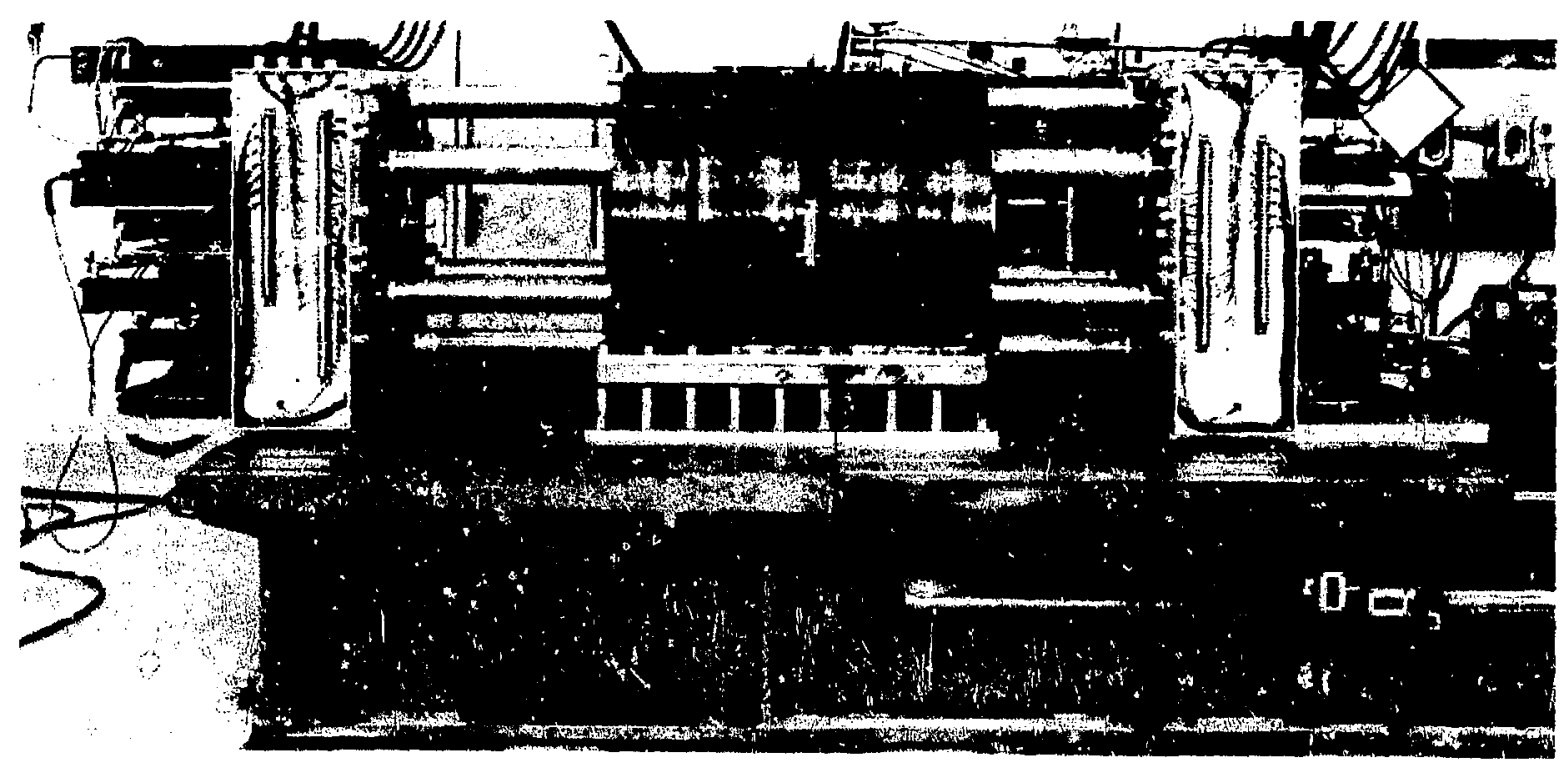

Fig. 15.

Big Ten as it appears during operation. When the assembly is shut down, the cart that holds the right-hand part of the assembly is retracted.

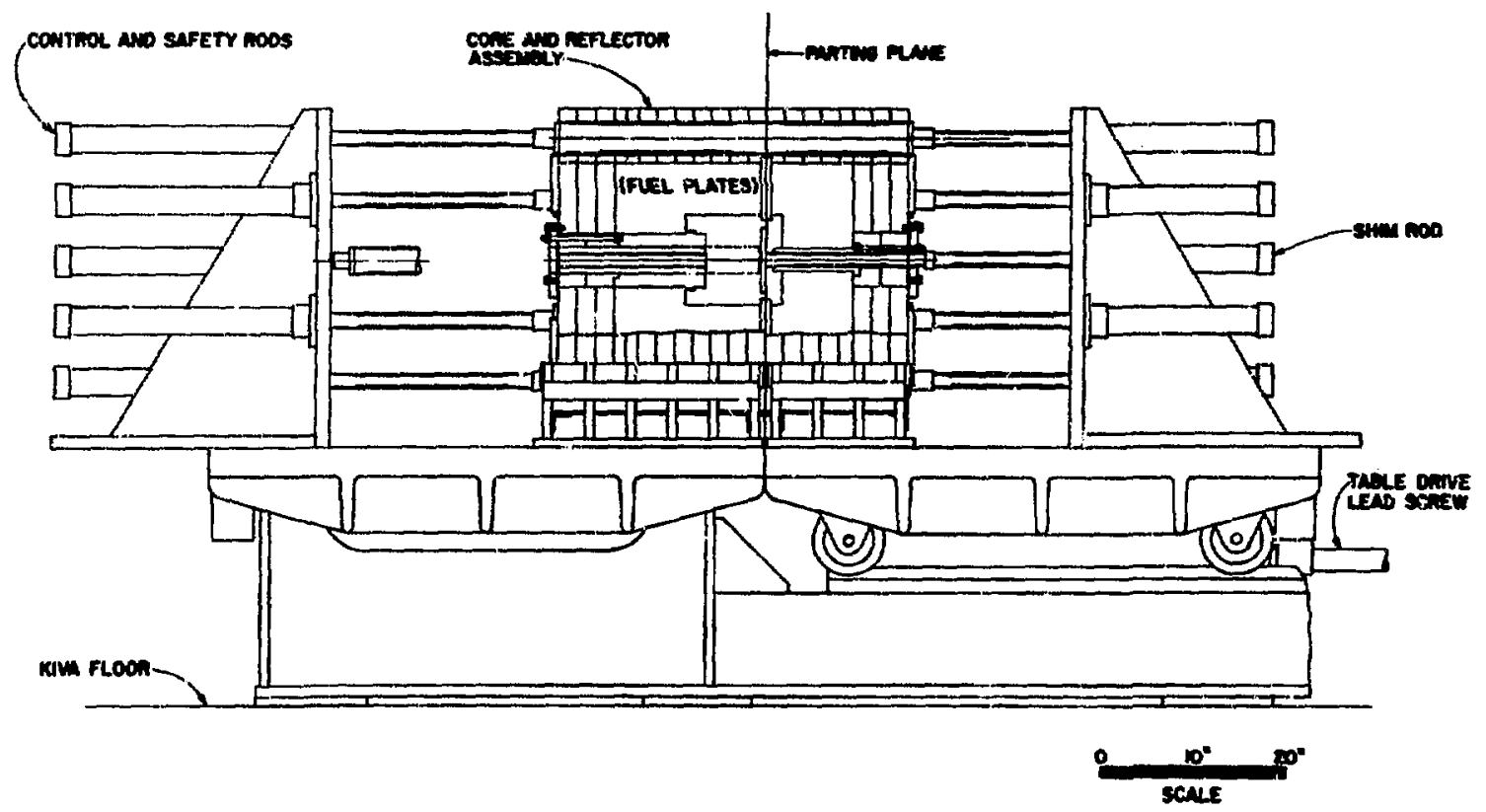

Fig. 16 .

Big Ten with cart in closed position. 


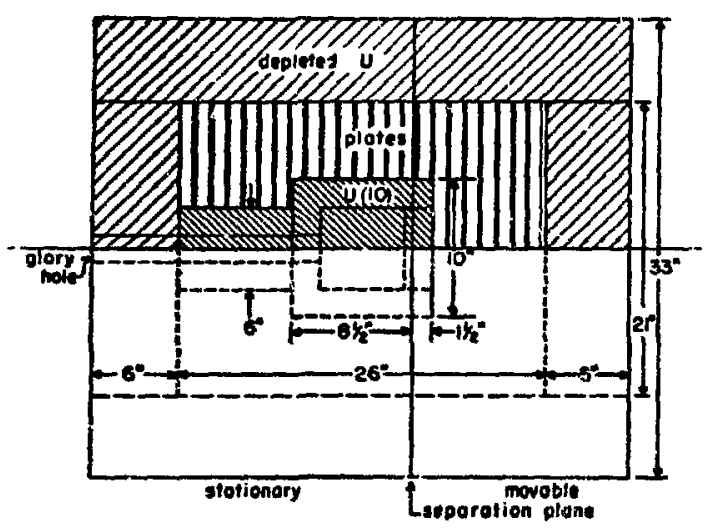

Fig. 17.

Basic Big Ten assembly.
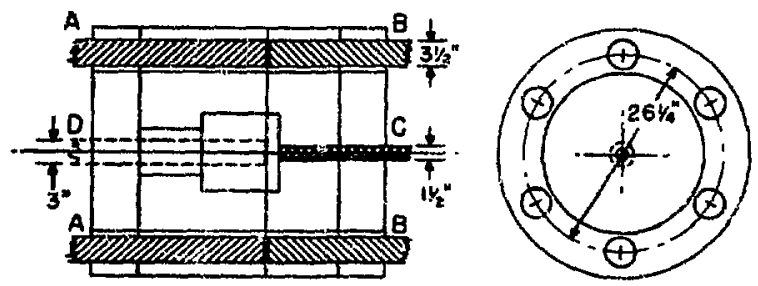

Fig. 18.

Big Ten control and safety rods. Rods $A$ are safety, $B$ and $C$ are control, and $D$ is the temporary combination rod for kinetic ex. periments.

automatic dropping of the lift) and for a vernier control. Static tests preliminary to Kinglet were conducted using this machine.

\section{Kiva 3 (Fig. 22)}

Kiva 3, with 18-in.-thick concrete walls and ceiling. is the only Kiva that has significant shielding. This shielding is to compensate for a 560 - $\mathrm{ft}$ distance to the nearest occupied building which is less than that from the other Kivas. Construction is such that reasonable confinement is expected in case of a relatively severe excursion. The one entrance to the main room is designed like a tunnel so that radiation scattering to the outside will be slight, and it is oriented so that it does not point toward the most frequently ocicupied areas.

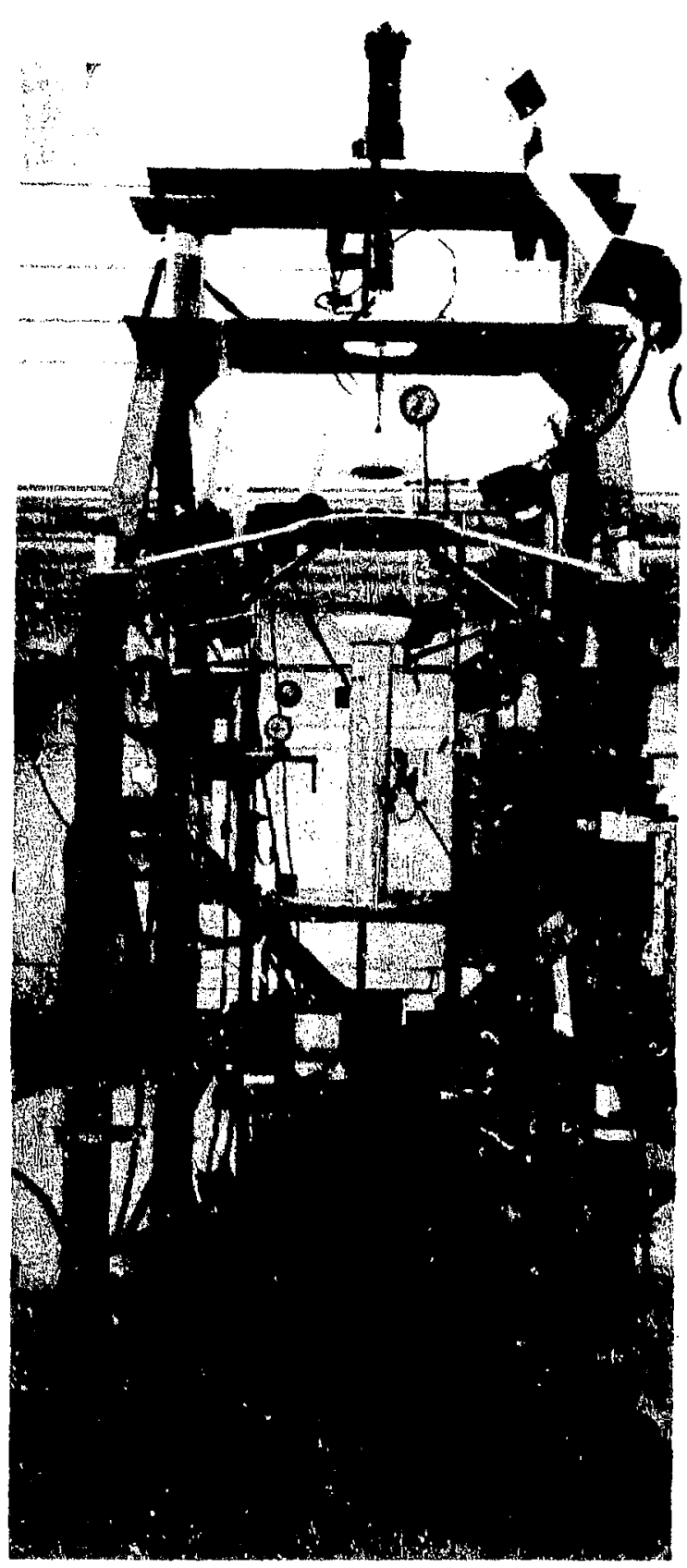

Fig. 19.

Comet with a plutonium core in composite reflector, for both subcritical and critical operation. 


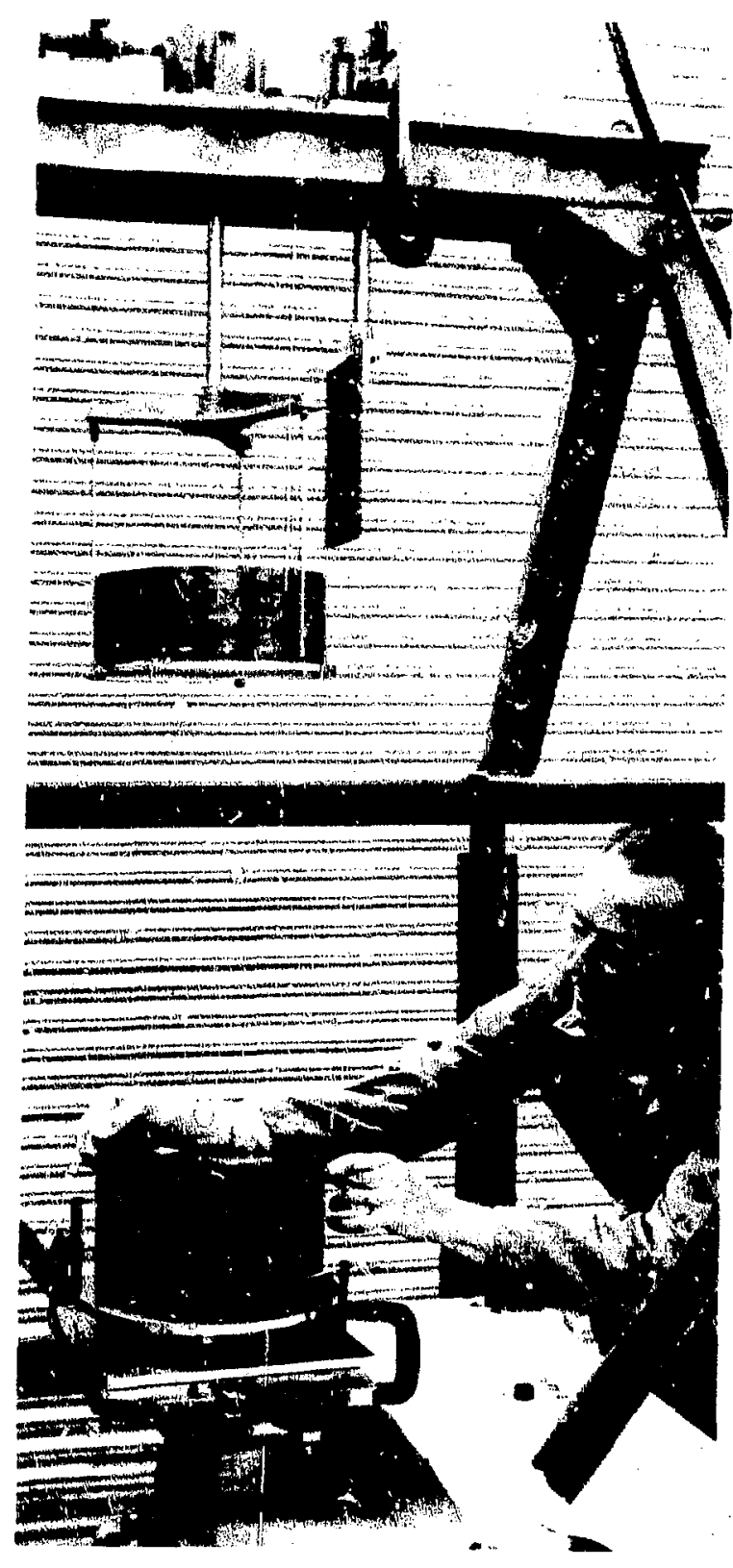

Fig. 20.

Jemima (17(37) critical assembly on Comet.

The following assembly machines are housed in Kiva 3.

1. Parka (Fig. 23). The Parka device is essentiai ly a Phoebus 1 reactor (without pressure vessel) that is used as a critical assembly. The system for actuating combined control and safety drums is a

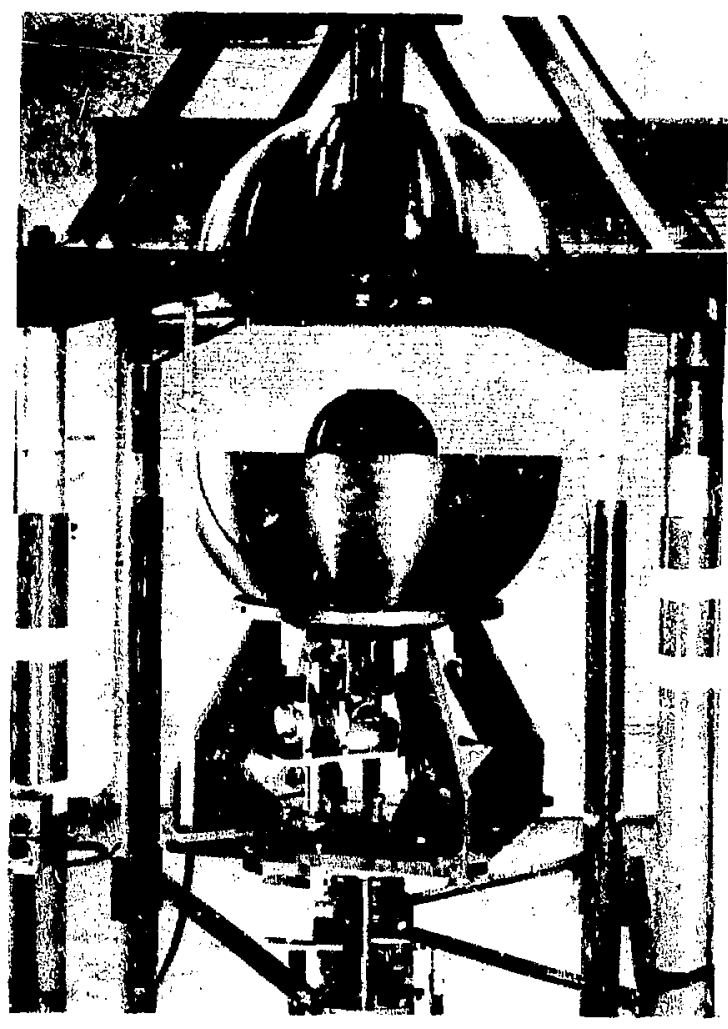

Fig. 21.

Tungsten-carbide critical assembly mounted on Comet. In this assembly for radiation calibration, a backup safety cylinder retracts at the top and a control cylinder enters from below.

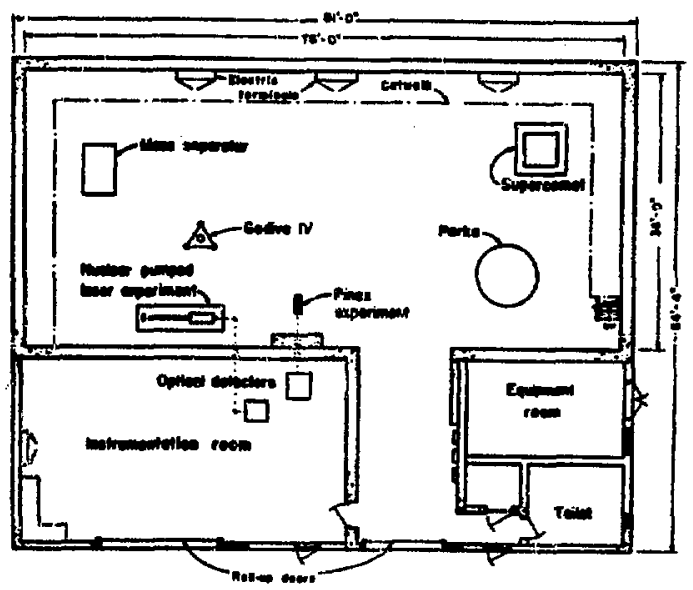

Fig. 22.

Kiva 3 floor plan. 


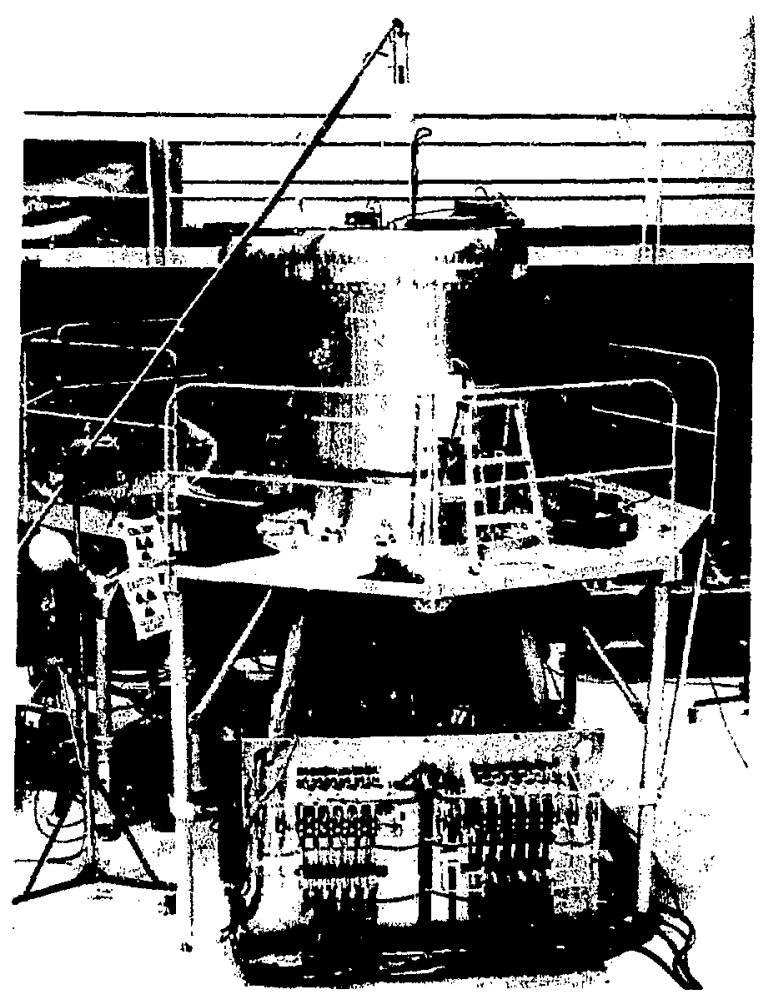

Fig. 23.

Parka in foreground with the TNT reactor positioned behind it for interaction experiments.

duplicate of that used for Rover tests in Nevada, with the following exception. For the measurement of transfer function, there is provision for continuous rotation, over a large speed range, of a special drum adjusted to have a reactivity swing of $\pm 0.1 \$$.

This feature was used during an unusual series of experiments in which Parka and the similar "TNT" reactor were operated simultaneously to measure neutronic inieraction at various separation distances. The pw wse was to evaluate complications that might arise as a result of clustering reactors in a propulsion vehicle.

Because the core of this assembly does not drop sut of the reflector, any change that might increase reactivity is made in steps that are small relative to the protective capability of the control drums. These drums have a total reactivity swing greater than $7 \$$, of which at least one-half is available for scram.

2. Godiva IV and IVA (Figs. 24 and 25). The Grodiva IV assembly is a successor of Isady Godiva

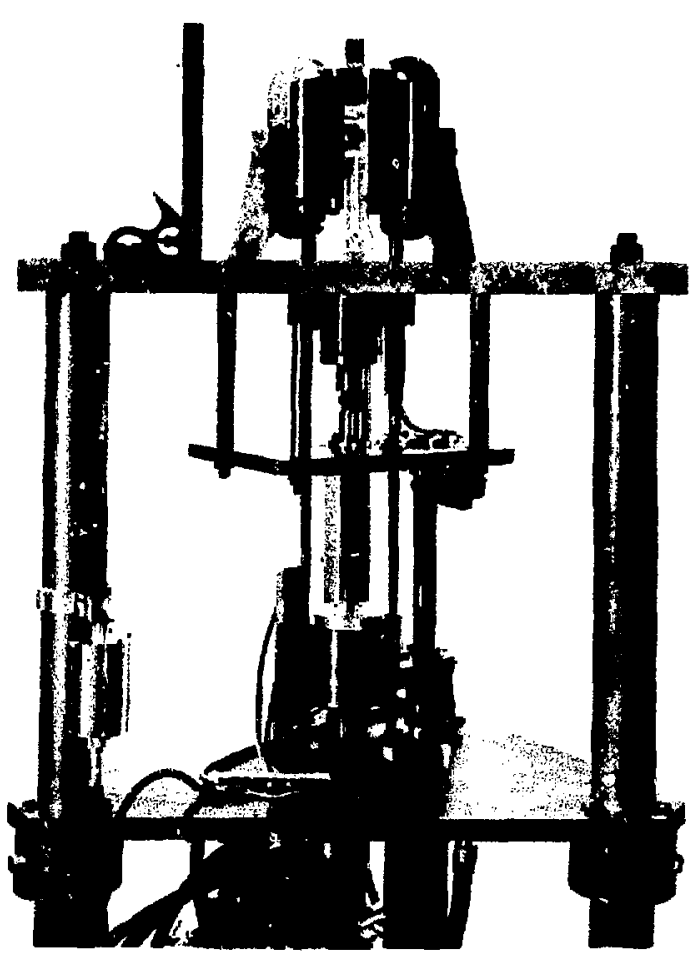

Fig. 24.

Gindiva IV experimental fast-burst assembly. $C$-clamps provide center-of-shock mounting for the uranium alloy head.

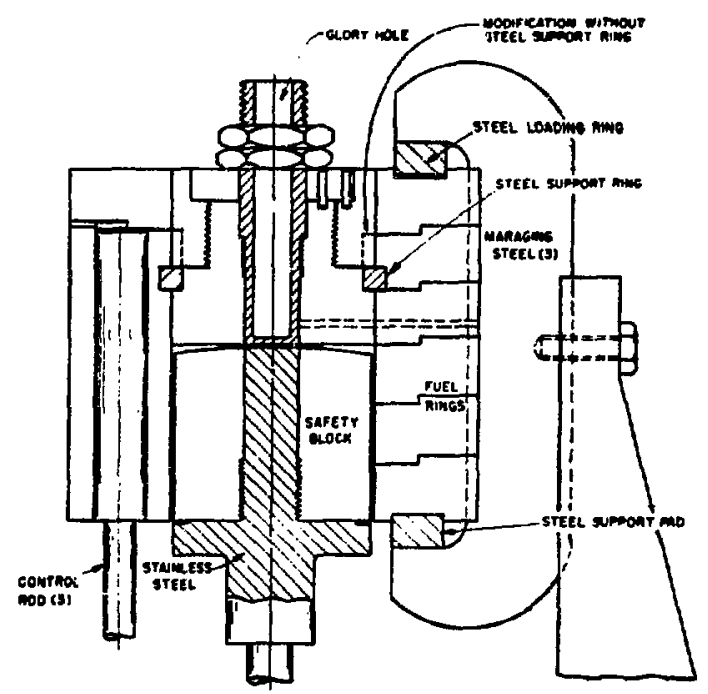

Fig. 25.

Godiva IV fuel assembly. 
with which reproducible superprompt-critical bursts were demonstrated, and of Godiva II that was designed specifically for fast burst production. Godiva IV is primarily an irradiation facility, although its original purpose was to test design features, including material selection, that are expected to increase resistance to shock damage.

The two major U(93)-alloy parts of Godiva IV, a stationary head and a movable safety block, form an essentially unreflected cylinder when brought together remotely. In this condition, delayed criticality can be attained by adjustment of two $U(93)$ control rods (each worth about $1.5 \$$ ) that enter the head. From this state, a burst may be produced, following a further slight adjustment of control-rod position, by a sudden reactivity addition of $1 \$$ brought about by insertion of an interlocked U(93) burst rod. Thermal expansion terminates the burst, and the associated shock ejects the safety block.

The production of a burst of known magnitude involves a well-defined cycle that includes a delayedcritical check, retraction of the safety block to allow decay of the neutron population, control adjustment to trim excess reactivity as required for the desired burst while allowing for temperature drift, reinsertion of the safety block, and, finally, burst-rod insertion. Interlocks prevent major departures from this cycle. The burst actuates a scram signal, which deactivates a magnet that normally secures the safety block. and ejects the burst rod.

Godiva IVA is essentially a duplicate of Godiva IV so that tests of design features for shock resistance can be resumed without jeopardizing availability of one assembly for irradiations.

3. Supercomet (Fig. 26). Supercomet is a general-purpose assembly machine, similar to Comet of Kiva 2 except for a longer hydraulic lift stroke. The principal automatic disassembly action is dropping of the lift.

Assemblies set up on this machine have been the mockup of a conceptual reactor fueled with plasma thermoelectric cells, a preliminary version of Pewee $Z_{1}$ po, and a system for establishing precisely the critical mass of an $\alpha$-phase plutonium sphere in water. Although there is no present plan for Supercomet operation, the machine remains available.

\section{GROUP R-5}

Although Group R-5 conducts critical experiments, it is also concerned with computational programs that parallel these experiments, with radiation effects and reactor safety studies that are

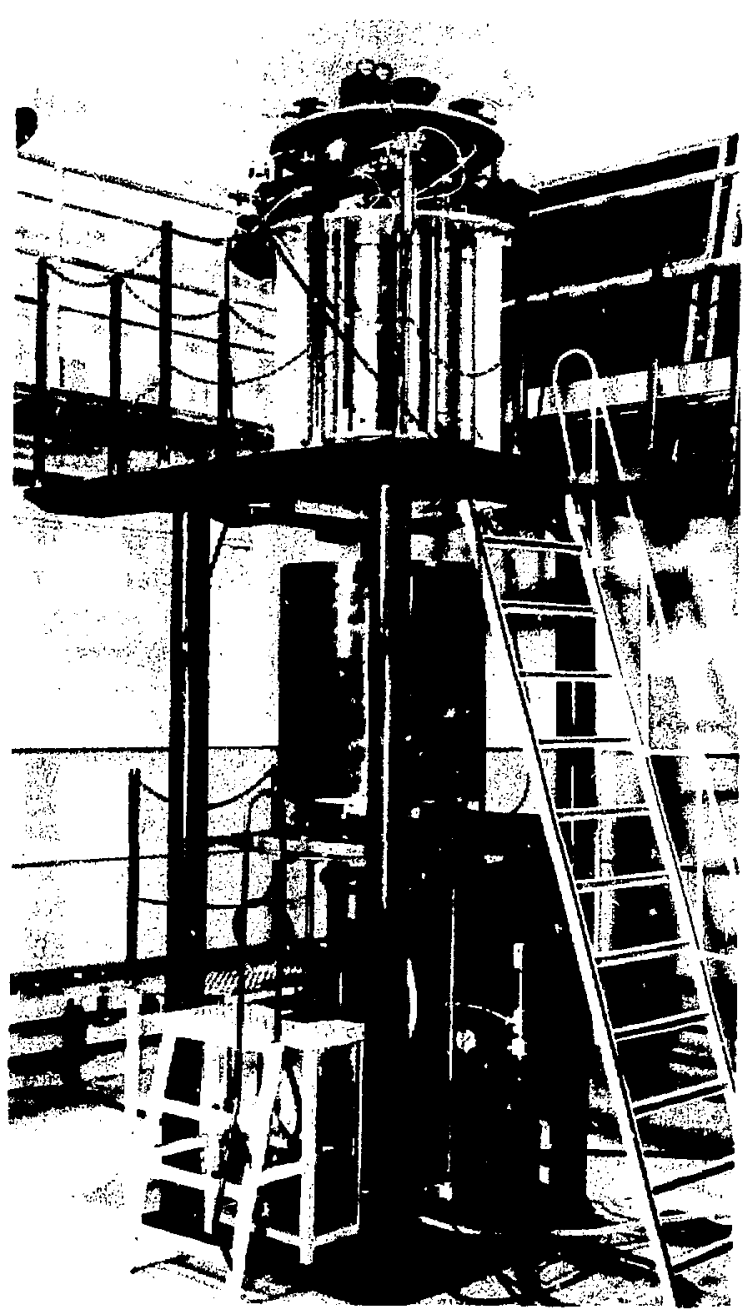

Fig. 26.

Supercomet with mockup of plasma thermocouple reactor. Water tank on lift rises to surround fuel structure mounted above.

primarily computational, with development of specialized instrumentation, and with neutron physics research that does not involve criticality. Consequently, only about two-thirds of the Group's members perform critical experiments. Personnel reached a peak of 43 in 1966 and dropped to 15 upon termination of the Rover Program in 1973. The mid1975 membership of $19-1 / 2$ is expected to increase somewhat. At this time, all the criticality experimentalists have been with the group $14 \mathrm{yr}$ or longer. There are no "operators" as a class.

As a result of lengthy tenure, training has not been a severe problem. In addition to formal training. persons assigned to the Group temporarily, as for 
summer employment. and those who assist with experiments for other Laboratory groups, serve as extra members of operating crews until judged by the Group Leader to be capable of fo:mal participation. In any event, an experienced permanent memher of the Group is in charge of operation. New experimentalists will be trained similarly.

Everyone within Group R-5 is encouraged to become familar with each critical experiment and to express his thoughts about it. One of the objectives, of course, is to reduce the possibility of "blind spots" concerning safety matters. Interest is broadened by discussions at weekly Group meetings, by making pertinent documents available, and by activities of an internal Safety Committee that advises the Group Leader. Because a major function of this Committee is to assist in the satisfactory blending of safety provisions with other objectives of a critical experiment, discussions are generated which go beyond the persons immediately concerned with design and operation. The Committee also alerts the Group to possible safety deficiencies that show up in the course of operation. Discussions such as these seem to contribute to a continuing respect for fissile material, and certainly improve understanding of the hazard involved and of methods for its control.

In the view of Group R-5, 28 yr of experience with critical facilities has dispelled most of the mystery associated with this hazard, and has refined and confirmed practices for criticality control. An extension of this view is that the philosophy underlying conventional industrial safety is appropriate for criticality safety. Certain aspects of this philosophy that Group members try to keep in mind are:

- Safety is an acceptable balance of risk against benefif (it is meaningless as a concept isolated from other groals): a corollary. implied earlier. is that safety should be considered as one of the goals of design and operation. not something supe'tposed.

- Safety provisions should be based upon experience and upon the responsive awareness of those perfor. ming operations; the protection of people has priority over protection of property.

- Safety responsibility (and commensurate authority) should be close to the operation: the attitude that "someone else is taking care of us" must be avoided. Alt hough authority and responsibility for an operation are inevitably assigned to an individual, a feeling of responsibility bv all concerned with the operation should be nurtured.

- Where alternatives exist (as is usual for criticality control), simple, convenient safety provisions are more effective than complex or awkward arrangements; any rule that requires use of a particular alternative arbitrarily should be avoided.

- Contributions to safety that cost little in money or convenience should be searched for and adopted even if they seem redundant.

\section{OPERATING PROCEDURES}

The Pajarito critical facility and its operating group :.ere born with documentary requirements, imposed as a natural reaction to two fatal handassembly accidents. The scope of operation, and general procedures were defined by Pajarito Operating Regulations from which no departure was permitted. Supplementary procedures specific to an experiment were covered by an approved Experimental Plan as required by the Regulations. It is still a requirement that each critical or near-critical operation he covered by an experimental Plan. (An example appears as Appendix A.)

As experience accumulated and demands for critical experiments broadened, the Regulations of 1947 inevitably evolved so as to become less rigid but even more effective. In the course of this evolution, the Regulations became general operating procedures, generated within the Critical Experiments Group but requiring approval at higher level. Departures from the procedures are permitted if spelled out in Experimental Plans that are also suhiect $t o$ the higher level approval. In general, changes of content were consistent with development of the safety philosophy outlined in the previous section. For example, the contribution by a "Safety Man," aloof from other experimental objec. tives, was recognized as marginal. As further illust ration. a complex emergency plan was replaced hv a simple, more flexible plan, based on local diagnostic measurements, as the understanding of hazards improved. ${ }^{2.3}$

The current (1973) version of the Regulations is Lus Alamos document LA-4037-SOP, Rev., "Operating Procedures for the Pajarito Site Critical Assembly Ficility."4 which supplements this report.

Briefly, these Procedures are in accordance with the American National Standard, "Safety Guide for the Performance of Critical Experiments" (Apper:dix B). but they provide much more detail. In the view of Group $R \cdot 5$, the most important function of the Pricedures is to protect penple who handle fissile material. Therefore, they emphasize a "handstacking limit" that corresponds to a value of 10 for idealized neutron multiplication (or three-ufuarters of a critical mass. where that is more 
significant). Storage and transfer practices are in accordance with American National Standard "Nuclear Criticality Safety Standard for Operations with Fissionable Materials Outside Reactors," $"$ and are designed to bo far below the quoted handstacking limit. Manual operations, such as loading the parts of an assembly. must be monitored and cont rolled so that the hand-stacking limit is not exreeded. The monituring requirements and associated procedures are consistent with the recent American National Standard "Safety in Conducting Neut ron-Multiplicat ion Mrasurements In Situ."

Next in importance are provisions for backing up protective feat ures built into the facility, that is, to maintain effectiveness of the isolation area during remole operation. These provisions include survey of the Kiva area (see Fig. 2) before operation. interlocks to prevent operation with the Kiva area gate open. captive-key actuation of the switch that controls power for the machine and use of the same key to open the gate, alarms to signal imminent operation. and flashing lights at the gate during operation.

Departures from procedures for handling fissile material would be permitted only for special svitems, such as certain weapon configurations that are known to remain subcritical under all conditions 10 be encountered. The provisions for departures prermitted hy Experimental Plans are intended to apply primarily to procedures whose purpose is to provent accidental excursions during remote operation or to limit the consequences of such excursions.

The procedures define minimum scram capalility and call for fail-safe s'ram actuation, duplicate sets of radiation monitors. and multiple scram mechanisms for critical operation. Interlocks serve (1) (1) prevent the assembly of major components unless vernier controls are at minimum reactivity and a scram monitor is active. () establish the asiembly sequence, and $(: 3)$ prevent operation of any vernier control device before major parts are brought together. Also specitied are two channels of startup instrumentation and one for automatically recording the neutron flux level during critical operation. as well as appropriate selector swilches, presition indicators. and indicator lights at the comtrul console. Multiplication limits apply to sul). critical assemblies. and for critical assemblies there are limits on overall react ivity and rates of reactivity addition. Principal modifications of the Procedures by Fxperimental Plans are adjustments of these limits where justified by reproducibility of the system and as required for kinetic or dynamic measurements such as those with Godiva IV and Kinglet.
As stated in the Operating Procedures, the LASI. Reactor Safety Committee (as of 1968) is responsible for general surveillance of Pajarito Facility activities, including matters of technical execution as well as policy. The R-5 Safety Committee is a technical resource of the Group Leader.

Finally, the Operating Procedures and content of Experimental Plans are constrained by overall limitations that appear in "Technical Specifications for the Pajarito Site Critical Experiments Ficility." 7 This document replaces "Operating I.imits for the Los Alamos Critical Assembly Facility." last revised in 1971. and it has ERDA approval. No departure from its provisions is permitted without formal concurrence of ERDA's Albuquerque Operations Office through the Manager of the Ias Alamos Area Office.

\section{PROTECTION OFFERED BY THE FACILITY}

The layout of the Pajarito Facility, and the Operating Procedures, offer effective radiological prolection for critical assemblies, although they would be inadequate for a power reactor. The effectiveness of protection is demonstrated by extrapolation of dose rates measured immediately outside cont rol rooms (in line of sight to the Kivas) during normal critical operations. Extrapolated excursion vields that give the (3-rem whole-body) LASL "administ rative" dose limit from direct radiation range from $10^{19}$ to $2 \times 10^{20}$ fissions, depending upon the tupe of assembly and the degree of shielding by Kiva walls. Immediately outside gates to the Kiva exclusion areas. the expossure might be twice that next to the control rooms, and within a control room it would be down by a factur of 5 because of added shielding loy concrete walls.

Operating experience demonstrates that this degree of built in protection is sufficient to allow for a multitude of obscure mishaps during remote operation. Of the 18 accidental prompt bursis in critical facilities which are described in the literature." vields of 7 were $10^{17}$ fissions or greater. and the maximum was $3.8 \times 10^{17}$ fissions. Damage incurred in all these bursts was small enough (1) represent an acceptable risk. The roughly two orders of magnitude difference between the maximum accidental yield and that required to induce a $3-\mathrm{rem}$ exposure at Pajarito Site constitutes a low-risk butfer zone. Together with the practices that have yroun from experience with critical operations. this generous buffer allows the flexibility required fur multipurpose experiments. 
There is even further safety guarantee in the form of fission-product restrictions that establish a large difference between the radiological hazards of our critical assemblies and those of power reactors. These restrictions appear in the Technical Specifications, one of them as a Safety Limit of $10^{19}$ fissions (within a limited period) based upon the above extrapolation of excursion yields. The other restriction, in the form of an Operating Limit, is that the fission-product power generation in any assembly, when averaged over the first hour after shutdown, shall not exceed $600 \mathrm{~W}$. This Operating Limit would be reached by an instantaneous burst of $10^{18}$ fissions, one-tenth of the Safety Limit. The tabulation and curves of Fig. 27 provide means of translating any fission history to fission-product power at any later time.

\section{KINGLET SAFETY ANALYSIS}

The Kinglet safety analysis report ${ }^{\prime}$ includes some of the trappings that carry over from power-reactor analvses, even though the fission-product inventory is minute by csmparison. Meteorological conditions and seismic potential are discussed, and Kinglet's estimated earthquake resistance (intensity VII MM) is typical of other assemblies and Kivas.

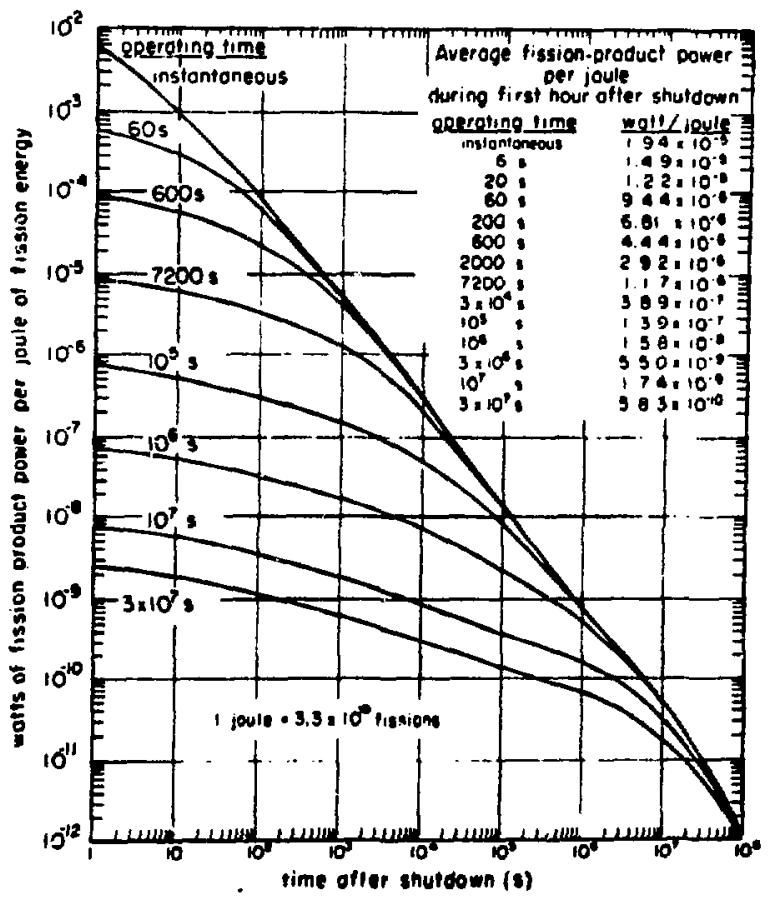

Fig. 27.

Fission-product power.
Although hypothetical fission-product release is a minor consideration for critical assemblies, the exercise of estimating doses from a resulting cloud was carried out for Kinglet. There the release of all tission products from a $10-\mathrm{s}$ run of $1.1 \times 10^{18}$ fissions (corresponding to the Operating Limit) in the most adverse conditions is shown to result in doses of less than $5 \mathrm{rad}$ whole body or $20 \mathrm{rad}$ to the thyruid at $1000 \mathrm{ft}$. the closest approach during operation. It is stated that realistic estimates would be about two orders of magnitude less, giving approximately 0.05 and 0.2 rad. respectively. The Kinglet results apply even more conservatively to the other Pajarito assemblies in which solid fuels tend to retain fission products.

\section{RISK EVALUATION}

\section{General Experience}

Since the first critical experiment at Oak Ridge. there have been $30 \mathrm{yr}$ of experience with critical assemblies. Because the damage potential of such assemblies is orders of magnitude below that postulated for power reactors, this experience provides a reasonable picture of the risk of operation. The associated accident history is summarized by Fig. 28. which shows the distribution of frequency of accidental prompt bursts vs ranges of fission vield.* (Accidents that predated current facilities are included.) The ordinate of the graph is scaled according to our estimate that total experience exceeds 50) assembly-vears (tallied over the active life of each assembly).

Bifore proceeding, one should note that precise conclusions cannot be expected from the accident statistirs, because there are so few high-vield incidents. and because of the practice of avoiding causes of past accidents which tends to make probability estimates larger than they should he. As we shall see, however, precise conclusions are not required to tell how we stand with regard to safety.

If the dashed line on the graph represents a plausihle extrapolation, as is usually assumed, we can form an idea of the probability of large accidental bursts. For example, the indicated probability of a $10^{1 ! !}$-fission burst is a negligible $10^{-5} / \mathrm{yr} / \mathrm{assembly.}$ A burst nearer $3 \times 10^{18}$ fissions in a small metal assembly could still damage the enclosure. For this

*Three sluggish power excursions in very large lowenrichment or natural uranium assemblies are not included because of their typically nonviolent nature. In these cases, prompt criticality probably uas not exceeded. 


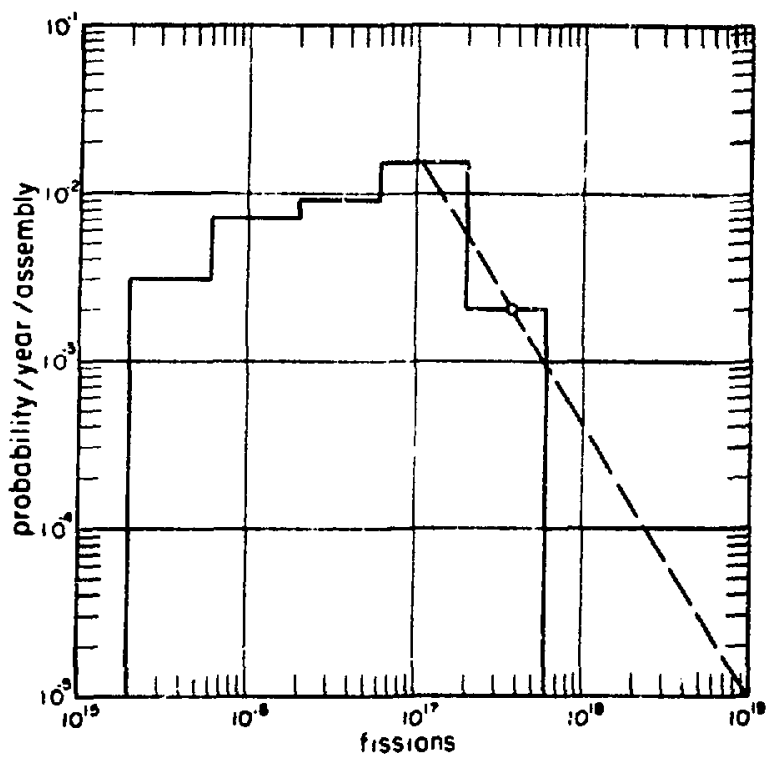

Fig. 28.

Acridental prompt bursts with critical assi'mblies.

yield, the probability would be $<10^{-4} / \mathrm{yr} /$ assembly. Even a severe loss of hundreds of thousands of dollars would combine with the latter probability of occurence to represent a risk of 10-100\$/yr. This risk would remain a small fraction of the value of opera. tion. even if our conclusions were in error by an order of magnitude.

\section{Pajarito Accident Experience}

More pertinent than the general review of critical assembly accidents is the experience that applies specifically to the Los Alamos remote-control facility. The eight accidental prompt-critical excursions* at this facility are identified in Table 1 . In addition to the usual total yield, fission density (per liter of enriched uranium) is included because of its closer relationship to damage.

The only personnel exposures were intentionally incurred upon Kiva reentry and were within acceptable limits. Damage of any value . esulted only from the two Lady Godiva incidents that involved prompt-burst operation. Property risk associated

"The present program of planned excursions with Godiva IV generated 700 prompt bursts by mid1975 , and it follows about 1000 bursts each using the original Lady Godiva and Godiva II. with this mode of operation is known to be greater than that from usual critical experiments.

After the first of these incidents, the cost of returning Lady Godiva to operable condition was about $\$ 600$. Direct cost of $\$ 2400$ for the other incident includes the estimated loss of $\mathrm{U}(93)$ from oxidation, as well as cleanup lal or, loss of electronic gear tor contaminated for service, and damage to the assembly framework. When a proper burst machine, Godiva II, became available, the forced retirement of Lady Godiva was considered a benefit instead of a loss. Although indirect costs such as investigation and reporting also may have beneficial aspects, part of them, say $\$ 200$ for each of the eight incidents, probably should be added to the direct costs.

The resulting $\$ 4600$ total is distributed over $28 \mathrm{yr}$ of operation, an estimated $80000-90000$ individual operations (startups), or, in the terms used in the preceding section, about 170 assembly-years. The indicated risk. $\sim \$ 160 / \mathrm{yr}$, although on the high side of the range suggested earlier, represents about $0.02^{\prime}$; of the annual operation cost.

It had been speculated that the Pajarito incidents from 1951 through 1957 might have been influenced by a strong feeling of urgency held over from the early weapon program. As part of an attempt to moderate this feeling and to discourage slapdash operations, the local Safety Committee was established in 1959 and given the functions mentioned above. Although there was little evidence of resulting improvement through the early 1960 's, the record of no inciderit within the last $8 \mathrm{yr}$ seems noteworthy.

\section{CONCLUSIONS}

We submit that safety provisions for the Los Alamos Critical Assembly Facility are commensurate with the radiation hazard; in other words, we conclude that experience-based protective features provide a favorable balance of risk vs benefit. There has been no significant personnel exposure, and the indicated property risk (including some incidental costs $\}$ is about $0.02 \%$ of the annual operation cost.

Although the hazard controls outlined here are more numerous and stringent than corresponding practices for conventional industrial safety, they allow reasonably convenient and flexible operation and are supported by the members of Group R-5. Thus, they do not invite deviation.

The radiation protective capability of the facility exceeds the requirements based on abundant experience by about an order of magnitude, supporting 
TABLE I

\section{ACCIDENTAL EXCURSIONS AT PAJARITO SITE"}

\section{Date}

Feb. 1951

April 1952

Feb. 1954

July 1956

Feb. 1957

June 1960

Dec. 1962

Mav :967
Assembly

Aquarium, two U(93) cylinders in water

Jemima, bare stact: of U(93) plates

Lady Godiva, burst-mode operation

Honeycomb, U(93) foils in graphite

Lady Godiva, burst-mode operation

Planet weapon study, reflected U(93) cylinder

Kiwi Zepn, U(93) foil and loaded graphite fuel

Pewee Zepo, fuel U(93) heads in graphite

after W. R. Stratton."

the contention that straightforward experiencebased controls are appropriate. Small fissionproduct inventory* eliminates the concern about public disaster which characterizes power reactors. whether the presumption is self-failure or escalation of a natural disaster that might arise from severe wind, flood, earthquake, or fire.

\section{REFERENCES}

1. T. F. Wimett, R. H. White, H. C. Paxton, and J. D. Orndoff, "Kinglet Safety Analysis," Los Alamos

"Note that $3 \times 10^{18}$ fissions, with which

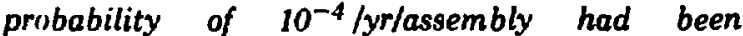
associated, is the number of fissions produced by a 1000-MWe power reactor in $0.03 \mathrm{~s}$.
Total Fission Density

Fissions (per liter of $U$ )

Damage

$1.0 \times 10^{17}$

$3.10 \times 10^{16}$

Slight oxidation

$1.5 \times 10^{16}$

$0.3 \times 10^{14 i}$

None

$5.6 \times 10^{16}$

$2.0 \times 10^{16}$

Slight warping of ting:3) pieces

$.3 .2 \times 10^{16}$

$1.0 \times 10^{165}$

None

$1.2 \times 10^{17}$

$4.1 \times 11^{16}$

Warping. oxidation. center neilr melting

$6 \times 10^{16}$

$2.3 \times 10^{16}$

Trivial

$3 \times 10^{16}$

$0.3 \times 10^{16}$

Nonte

$4.1 \times 10^{16}$

$0.5 \times 10^{16}$

None

Scientific Laboratory report LA-4797-MS (October 19711.

2. W. R. Stratton, "A Review of Criticality Incidents," Los Alamos Scientific Laboratcry report LA-3611 (September 1967).

3. H. C. Paxton, "Pajarito Plan for Radiation Emergency." Los Alamos Scientific Laboratory report LA-4037-SOP, Rev., Suppl. 1 (May 1973).

4. J. D. Orndoff and H. C. Paxton, "Operating Procedures for the Pajarito Site Critical Assembly Facility," Los Alamos Scientific Laboratory report LA-4037-SOP. Rev. (January 1973).

5. American National Standard. "Nuclear Criticality Safety Standard for Operations with 
Fissioniblie Materials Outside Reactors." ANSI Nifi.1-1975.

6. American National Standard, "Safety in Counductiny Neutron-Multiplication Measuremen!s In Silu." A.Nsi N16.3-1975.
7. H. C. Paxton, "Technical Specifications for the Pajarito Site Critical Experiments Facility." Los Alimos Scientific Laboratory report LA-6016-SOP (Novemher 1975). 
N-2-8276

Apri1 10, 1968

EXPLRTIENTAL PLAN NO. 170

SWATIC CRITICAL EXPARIMENT FOR THB KINGLET ASSEABLY

OPERATIOKAL LIMIT:

Stage 1: aultiplication $\leq 100$.

Stage 2: delayed critical operation with poattive periods 210 seconds.

Assembly Unchine:

conet in Kiva 2

Required Personnel:

two

Expected Starting Date: May 1, 1969

$$
<<<<>>>\rangle>
$$

Purpose. To eetablieb criticality conditions of liquid fuel ( ${ }^{235} \mathrm{v}$ sulfate solution) contained in beryllium-reflected zircaloy pipe to be uned in the dynanic experiment (IINGLET) for the KING renctor concept.

Active unterial. Initial fuel will be 12 ilters of aulfate eolution at 75 grans per 11 ter ${ }^{235} \mathrm{U}$. The expected copposition $180.3188 \mathrm{y}$ $\mathrm{UO}_{2} \mathrm{SO}_{4}+0.50 \mathrm{y} \mathrm{H}_{2} \mathrm{SO}_{4}+0.05 \mathrm{y} \mathrm{Fe}_{2}\left(\mathrm{SO}_{4}\right)+.01 \mathrm{ySO}$. An the experiment progresses, it uny becone neceeneng to nodify the $235_{U}$ concentration. This golution w111 be provided by CAB-8 and atored in a $5.5-1$. $-\mathrm{d} 1 \mathrm{an}$ container known as "rocket".

Assembly Description. The fuel solution will be contained in a 5-1n.dial, 72-1n.-10ng Z1rceloy ptpe as shown in Figure 1. The pipe 18 eupported on the hydraulic lift of conet. A near-cylindrical berylliu reflector with a radial thickness of 1210 , and height 20 1n. surrounds the pipe. The rellector is fabricsted from Be blocks bolted together to form acld reflector with an axial hole to accomodate the fuel pipe and a reactivity control chin aurround1ng 1t. The ohin is a longitudinally aplit eleeve of stainless steol with 30 alls Cd plated on 1ts outer aurface. Vortical notion of this control 18 provided by a linear hydraulic aervo actuntor mounted on top as shown. Remote position indicators for both shin and lift are located in the control room. 


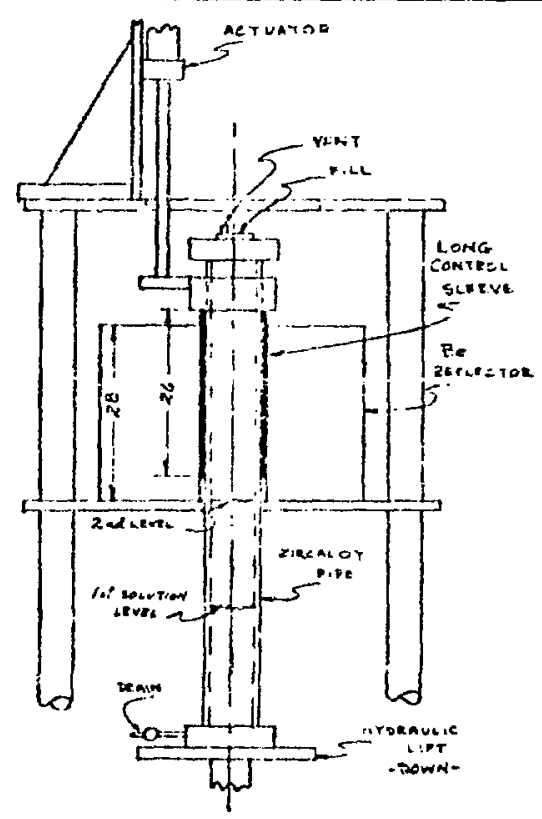

In this experiment the fuel level will be no nore than needed to extend above the upper reflector surface when the pipe or core is ralsed by the lift. Calculations indicate that reactivity is reduced by $\sim 40 \%$ ak by dropping the core below the reflector. A reduction of nearly that anount is expected when the 26-1n.-1ong Cd shim is positioned in the reflector with the Ift up.

\section{Procedure.}

Stage 1: For this series of mensuremente, the length of the shim $w 11$ be $26 \mathrm{in}$. With the $11 \mathrm{ft}$ down, the fuel solution w1il be poured into the pipe by adding wone liter at a tine through an orifice at the top. A neutron source will be located inside the pipe during this procedure, and neutron multiplication monitored by $\mathrm{Br}_{3}$ countere placed around the pipe. When the level reaches $\sim 16 \mathrm{ln} .$, filling will stop. With the control shin in the down position (See Figs. 1 and 2), the lift will be raised by remota control and noutron muitiplication observed as the fuel enters stepwise into the reflector. Por these measurements, detectors will be reloceted at the reflector gurface. Next the shim will be raised in stepe nonitored by neutron multiplication. (Neutron multiplication will be determined using unauliplied detector response from the same geometry but with water in place of fuel golution.)

Successive fuel additions, shown by precoding neasurements to be within hand-stacking linits followed by remote mearurements as above, will continue until extrapolation to criticality ls reliable.

If necessary to change the fuel concentration, solution will be drained through a valve indicated in the drawings at the borto of the pipe. Refueling will be accomplished in the sane manner 

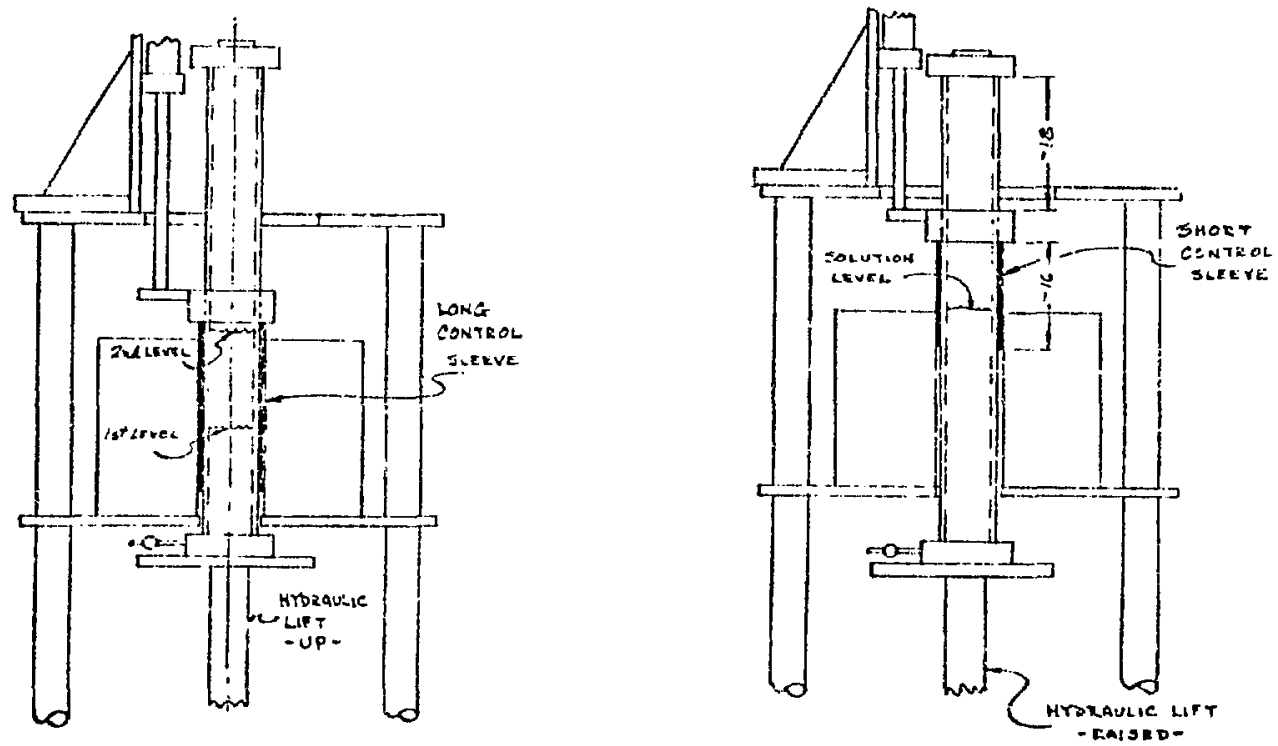

as for the first fillig. Solutions will always be stored in "rockets" when not in the assembly.

Stage 2: Baged upon results from stage 1, the length and travel of the shim will be reduced, and the fuel level adjusted, such that release of elther the shim or lift will provide adequate shutdown. See FIg. 3, which Indicstes the configuration that sinulates cond1tions in Kinglet. This permits w18 in. free lift travel for shutdow.

Wth two Independent means or shutdown established, the shin $\nabla 111$ be radged slowly toward the extrapolated critical position. After criticality is attained, the reactivity effectivenoss of components at various positions will be nessured. In particular, the control shin $\mathbf{w 1 1}$ be callbrated over 1 ts perminsible guporcritical travel. Such calibrations will be accomplished by positive pertod mensurement with periods $>10$ seconds.

A posalble nodification, in addition to change of aolution concentration, way arise from the need to test a control cylinder wth different materials than epecifled above. If nay buch nodification is not know to decrease the reactivity of earlier conpigurat1ons, Stage 1 mengurements $\mathbf{w 1 1}$ be repeated before entering Stage 2.

Safety Precautions. Although calculations predict a neutron multiplication less than ten for the entire core filled with fuel if the control shim is in its shutdown position, no more than a liter of fuel 18 allowed to be present at any time within the reflector during the anual $f \pm 111$ g operation. By pouring through a funnel or orifice, only a narrow etream of fuel is permitted. 
The Zircaloy pipe wijl be fitted with a vent in the top cap to prevent overstressing from an accidental pressure bulldup.

It is important to avold any manual operstion that would raise solution into the reflector. This will be prevented, except by renote costrol, because the solution pipe will be anchored to the 1ift. The only occasion for raising the pipe in the presence of personnel would be for replacement of the gplit shim. In this event, the solution will be drained beforehand.

Central-source multiplication, which is used as a safety index, is usually distorted for solution mensurements because neutron moderation and absorption effects on "unmultiplied" and "multiplied" responses generally differ. In this case, however, ORNL tlux measurements in the 5-in.-dian HFIR island indicate that such d1stortion will be gesall.

Subnit ted by:

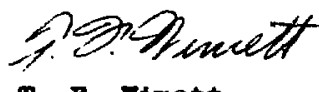

T. F. Wimett

Approved by:

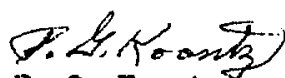

P. G. Koontz

N-2 Safety Comittee

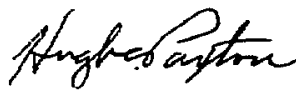

月. C. Paxton

N-2 Group Leader

f.W. Spunce

R. W. Sptnce

N-DAvision Leader 


\section{APPENDIX B}

\section{AMERICAN NATIONAL STANDARD N405-1975 \\ SAFETY GUIDE FOR THE PERFORMANCE GF ('RETICAL EXPERIMENTS}

\section{SCOPE}

This Safety Guide for the performance of critical experiments is intenderi for universal applicability and is formulated in general terms in order to avoid imposing undue linitations on specific local experiment practices.

\section{DEFINITIONS}

\subsection{Limitations}

The definitions given below are restrictive for the purpose of $t$ his st andard. Other specialized terms are defined in American National Standard Glossary of Terms in Nuclear Science and Techrology, Ni.1. 1975. or have definitions arcepted by usage.

\subsection{Glossary of Terms}

2.2.1 Shall, Should, and May. The word "shall" is used to denote a requirement, the word "slinuld" to denote a recommendation, and the word "nay" to deniste permission, neither a requirement nor a recommendation. In order to conform with this Standard all operations shall be performed in accordance with its requirements, but not necessarily with its recummendations.

2.2.2 Management. The administrative body to which the supervision of a critical facility reports.

2.2.3 Critical Experiment (Experiment). An experiment or series of experiments performed with fissionable material which may be at or near nuclear criticality. The principal purpose is the study of neutron behavior within a critical assembly.

2.2.4 Critical Assembly (Assembly). A device or physical syst em for performing critical experiments. The energy produced by fission in a critical assembly is insufficient to require auxiliary cooling. and the power historv is such that a sigrificant inventory of long-lived fission products is not accumulated.
2.2.5 Criticality Accident. The release of energy as a result of accidentally producing a selfsustaining or divergent neutron chain reaction.

2.2.6 Assembly Area. A region in the vicinity of a critical assembly where there would be inadequate personnel protection in the event of a criticality arcident.

2.2.7 Neutron Source. Any material, combination of materials, or device emitting neutrun:, including materials undergoing fission.

2.2.8 Safety Device. A mechanism designed to reduce the reactivity of a critical assembly.

2.2.9 Scram. A rapid reduction of reactivity to suhcriticality.

\section{ADMINISTRATIVE' PRACTICES}

\section{1}

Written general operational restrictions for each critical facility, based on consideration of characteristics including shielding and confinement, shall be approved by management.

\section{2}

Fach new experimental program shall be documented, reviewed, and approved internally in a manner estahlished by management.

\section{3}

Operations shall be planned so that no single operational action or procedural violation could lead tn a criticality accident. Planned superprompt criticality is not subject to this restriction. Guidance for performance of experiments of that type is given in American National Standard for Operation of Fast Pulsed Reactors, N:194-1975. 
Betore an experiment begins, the operational and salety aspects shall be reviewed by all who are expected to take part in the operation.

\section{5}

Responsibility and commensurate authority for the safe operation of eritical experiments shall be assigned unambiguously and singularly through line crganization by management.

\section{6}

At least two persons having qualifications approved iy management shall be present while a critical experiment is being performed.

\section{7}

Manual operations with fissionable material, such as nonremote addition of reactivity to an assembly, transfer, and storage, shall be in accordance with American National Standard for Nuclear Criticality Safety in Operations with Fissionable Materials Outside Reactors, N16.1-1975.

\section{8}

Additions of reactivity beyond those permitted by 3.7 shall be made by remote operation. Such additions shall be continuously adjustable except when the resulting reactivity is known with an accuracy such that salety will not be compromised.

\section{9}

No person shall enter an assembly area during the performance of a critical experiment without the approval of the person responsible for safety.

\subsection{0}

During an addition of reactivity that requires remote operation, personnel shall be protected from any undesirable quantity of energy that might be liberated as the consequence of accidental criticality.
If anyone participating in the operation of an experiment expresses doubt of the safety of a particular action or step, the experiment shall be suspended until the doubt is resolved.

\subsection{2}

A record of the status and operation of the assembly with particular reference to its safety features shall be maintained until the value of the records has no influence on the safety of future operations.

\subsection{3}

An emergency plan approved by management shall be in effect.

\subsection{4}

There shall be provisions for radiation monitoring, jersonnel dosimetry, and contamination control, for both normal and emergency conditions. Guidance for dosimetry following a criticality accident is contained in American National Standard Dosimetry for Criticality Accidents, N13.3-1969.

\subsection{5}

There shall be a review, at least annualiy, of the administrative and operational prartices b: a group independent of the facility staff.

\section{DESIGN CRITERIA}

\section{1}

There shall be safeguards against operation of critical assembly equipment by unauthorized personnel.

\section{2}

Communication shall exist between personnel at the control console and those who may be at the critical assembly. 
A signal audible to personnel within the assembly area shall provide an indication of the neutron flux during adjustments that may affect reactivity.

\section{4}

A source of neutrons sufficient to produce a meaningful indication of multiplication shall be present during any approach to criticality by remote operation, except that special experiments may be performed without a source provided reactivity effects are known with an accuracy such that safety will not be compromised.

\section{5}

Each assembly shall be provided with at least one safety device that is actuated automatically at a preset radiation level and can be actuated manually. This device shall be capable of reducing the reactivity of the assembly to a value no greater than that at which remote operation, as described in 3.8 , is required. This device shall also be capable of removing reactivity more rapidly than it can be added by any normal operation.

\section{6}

At least two neutron or gamma-ray detectors together with associated electronic and mechanical components shall be capable of independently initiating a scram of the assembly at a preset radiation level.

\section{7}

Loss of actuating power to any safety device shall produce a scram.

\section{8}

A scram signal shall preclude operational increase of reactivity.
During critical experiments there shall be at least two instruments providing indication of the neutron flux within the assembly. These may be the same as those required by 4.6 .

\subsection{0}

The status of any variable for fine control of reactivity shall be continuously displayed at the control console. The limiting conditions or positions of safety devices shall also be displayed.

\section{OPERATIONAL PRACTICES}

\section{1}

The satisfactory performance of newly installed or significantly altered control equipment or safety devices shall be established before subsequently achieving criticality.

\section{2}

The frequency of periodic maintenance should be commensurate with the safety consequences of failure.

\section{3}

The proper functioning of the required number of safety devices shall be established prior to starting operations each day that an experiment is to be initiated. In the course of these tests or early in each dav's operation, the response of each required detector svstem to a change in neutron or gamma-ray level shall be noted.

\section{4}

Additions of reactivity requiring remote operation shall he guided by neut ron detector response. During an initial approach to criticality, reactivity shall not he added unless the effect of any preceding addition has heen observed and understood. 
distinct methods (e.g., by rod motion and by water

'The safety consequences of any unexpected behavior of the assembly or its associated equipment shall be evaluated promptly and prior to further operation that could lead to a criticality accident as a result of such hehavior.

\section{6}

Additions of reactivity requiring remote operation shall not be made simultaneously by two or more peisons, unless the effect of such additions has been measured.

\section{7} addition), unless the effect of such additions has been measured.

\section{REVISION OF AMERICAN NATIONAL STANDARDS REFERRED TO IN THIS DOCUMENT}

When the following American National Standards referred to in this document are superseded by a revision approved by the American National Standards Institute, Inc. the revision shall apply:

Glossary of Terms in Nuclear Science and Technology, N1.1-1975.

Dusimetry for Criticality Accidents, N13.3-1969.

Nuclear Criticality Safety in Operations with Fissionahle Materials Outside Reactors, N16.1. 1975.

Additions of reactivity requiring remote operation shall not be made simultaneously by two or more 